\title{
Ein bibliographischer Überblick über die kanonischen Texte der Srāvakayāna-Schulen des Buddhismus (ausgenommen der des Mahāvihāra-Theravāda)
}

\author{
Für Lambert Schmithausen \\ als kleines Zeichen eines großen Dankes
}

Die Erforschung der kanonischen Literatur der Hīnayāna-Schulen des Buddhismus ist mittlerweile so komplex geworden und erfordert die Kenntnis einer solch großen Anzahl von alten wie modernen Sprachen, ${ }^{1}$ dass es demjenigen, der sich als dilettante mit ihr beschäftigt, eigentlich nicht ansteht, einen Aufsatz ${ }^{2}$ wie den nachfolgenden zu veröffentlichen. ${ }^{3}$ Dass dessen Verfasser dies dennoch wagt, geschieht vor allem aus dem Grund, dass sich mit Hilfe einer Sammlung von Veröffentlichungen zu den kanonischen Texten buddhistischer Schulen, die für die Ausarbeitung des Handbuchbeitrags "Heilige Schriften des Buddhismus" (Oberlies 2000) angelegt und aufbereitet worden war, in den letzten Jahren verschiedene an den Vf. gerichtete Anfragen betreffs kanonischer Texte beantworten ließen und es demnach zu vermuten stand, dass sich eine Veröffentlichung dieser Sammlung - trotz all ihrer Lücken - doch lohnen könnte. Nach diesen einleitenden Sätzen muß nicht eigens betont werden, dass sich der Vf. der vielen, vielen Unzulängigkeiten des nachfolgenden bibliographischen Überblicks über die kanonischen ${ }^{4}$ 'Texte

1 Bei der Arbeit an und mit textlichen Zeugnissen ist überdies die Kenntnis einer großen Zahl von Schrift(system)en unabdingbar.

2 Die Sigla für Titel von Pāli-Texten - jeweils in der Standard-Edition der Pāli Text Society - sind die des Critical Pāli Dictionary.

3 Es sei dies der Ort, daran zu erinnern, dass es eines der vielen Verdienste des Mannes ist, dem dieser Aufsatz gewidmet ist, die Diskussion um die Schulzugehörigkeit buddhistischer Textzeugnisse in seinem Aufsatz "Zu den Rezensionen des Udānavargaḥ" (Schmithausen 1970) entscheidend mitangestoßen zu haben.

4 Im Falle der Abhayagiri(vihāra)vāsins wurden auch bibliographische Hinweise zum nach-kanonischen Schrifttum - soweit bekannt - gegeben. Und auch sonst bot es sich an, hier und da solche Texte in die Darstellung miteinzubeziehen. Von diesen Ausnahmen abgesehen habe ich mich jedoch ganz auf die Verzeichnung von Veröffentlichungen zu den kanonischen Texten beschränkt. 
der Śrāvakayāna-Schulen des Buddhismus ${ }^{5}$ nur allzu schmerzlich bewußt ist. ${ }^{6}$ Als Entschuldigung für einige wenige der zahlreichen lacunae mag allenfalls dienen, dass dem Vf. nicht alle relevanten Zeitschriften und Monographien greifbar waren ${ }^{7}-$ auch nicht an den verschiedenen Orten, an die ihn seine berufliche hind $\imath$ in den letzten Jahren verschlagen hat. ${ }^{8}$

Dass ein solcher Überblick ${ }^{9}$ überhaupt notwendig ist, liegt an der Aufspaltung des frühen Buddhismus in verschiedene Schulen, die Folge war von Streitigkeiten, die Ordensdisziplin und Lehre betrafen. ${ }^{10}$ Hatte sich eine neue Schule gebildet, war sie bemüht, sich zu "definieren". Zu diesem Zweck wurden zumeist (örtliche) Synoden einberufen, deren wichtigste Aufgabe es war, den Wortlaut der Texte festzulegen. In den buddhistischen Texten finden sich umfangreiche Berichte über diese (sog.) Konzile, ${ }^{11}$ die zwar von Schule zu Schule in Einzelheiten stark voneinander abweichen, aus denen sich aber ein gemeinsamer, wohl

5 Ausgenommen ist die des Mahāvihāra-Theravāda, da mit von Hinüber 1996 ein in jeder Hinsicht umfassender Überblick über die Literatur dieser Schule vorliegt.

${ }_{6}$ (Unerreichtes) Vorbild war mir der Guide to the Literature of Khotan (Tokyo 1992) meines - leider allzu früh verstorbenen - Lehrers R.E. Emmerick.

7 So habe ich Kenntnis etwa von Kōza Tonkō 6: Tonkō kogo bunken ("The literatures in barbarian languages from Tun-huang" [Tokyo 1985]) nur aus IIJ 29 (1986) 231.

8 Viele Freunde und Kollegen standen mir bei der Ausarbeitung dieses Überblicks mit Rat und Tat zur Seite. Sie alle zu nennen, würde den Platz dieser Fußnote sprengen. So mag man es mir nachsehen, wenn ich hier nur diejenigen nenne, bei denen ich wiederholt Auskünfte (und Sonderdrucke) eingeholt habe: Siglinde Dietz, Helmut Eimer, Fumio Enomoto, Jens-Uwe Hartmann, Oskar von Hinüber, Noriaki Hosoda, Kazunobu Matsuda, Lore Sander, Lambert Schmithausen, Klaus Wille und Peter Wyzlic. Ihnen allen - und natürlich auch allen Nichtgenannten sei auch an dieser Stelle herzlichst gedankt.

9 SHT-Nummern wurden in der Regel nur dann angeführt, wenn keine separate Edition (in Form eines Aufsatzes und/oder einer Monographie) vorliegt. In diesem Falle lassen sich diese über die zitierte Sekundärliteratur leicht ermitteln. Normal gedrucktes SHT mit folgender römischer und durch Spatium getrennter arabischer Zahl verweist auf Textfragmente, kursives SHT mit folgender römischer und durch Schrägstrich getrennter arabischer Zahl hingegen auf die Kataloge.

${ }^{10}$ Gewiß führte aber auch die zum Teil weite räumliche Trennung der buddhistischen Gemeinden zu (regionalen) Sonderentwicklungen.

11 Zusammenfassend zu diesen siehe Vf., Besprechung von H. Bechert et al., Der Buddhismus I: Der indische Buddhismus und seine Verzweigungen. Stuttgart 2000, in: $G G A$ (2002) 208-209. 
historischer Kern herausschälen läßt. Es scheint sicher, dass es zu einem ersten Schisma der buddhistischen Gemeinde auf einem Konzil gekommen ist, das vermutlich gegen Mitte des dritten vorchristlichen Jahrhunderts in Pātaliputra, dem heutigen Patna, stattfand. Folge davon war die Spaltung der Gemeinde in Mahāsāṅghikas und Sthaviravādins. ${ }^{12}$ Von den letztgenannten spalteten sich später die Vātsīputrīyas ab, und dann trennten sich die verbliebenen Sthaviravādins in die Vibhajyavādins und die Sarvāstivādins. Die Vibhajyavādins ihrerseits zerfielen in die Schulen der Mahīśāsakas, Dharmaguptakas, Theravādins und Kāśyapīyas. Ähnliche Schismen erfaßten auch die Mahāsāṅghikas, und es kam zur Entstehung der Schulen der Lokottaravādins und Caitikas, aus denen wiederum (u.a.) die Pūrva- und Aparaśailas ${ }^{13}$ hervorgingen.

\section{Die Abhayagiri(Vihāra)vāsins ${ }^{14}$}

1. Wie der Kanon der Mahāvihāra-Theravādins so ist auch derjenige der Abhayagiri(vihāra)vāsins in Pāli verfaßt. Auch scheint er sich nur in Einzelheiten von jenem unterschieden zu haben. ${ }^{15}$ Und als der Buddhismus auf Ceylon unter König Parakkamabāhu I. (1153-1186) reformiert und die Abhayagiri(vihāra)vāsin-Mönche nach Mahāvihāra-Tradition reordiniert wurden, brach die Überlieferung dieses Kanons völlig ab. Es mag daher nicht wunder nehmen, dass bislang mit dem (a) Vinaya-Khandhaka und dem (b) Buddhavạ̣sa lediglich zwei alte Texte der Abhayagiri(vihāra)vāsins, der zweiten großen Untergruppe der ceylonesischen Theravādins, bekannt geworden sind, und selbst dies nur aus sehr kurzen Zitaten, von denen das des zweitgenannten Textes so-

12 Die Überlieferung geht, was die "tatsächlichen" Vorgänge anbelangt, allerdings weit auseinander.

${ }^{13}$ Aus dem Kanon der Pūrvaśailas zitiert Candrakīrti (6./7. Jh.) in seiner Prasannapadā (s. P. Harrison, Sanskrit Fragments of a Lokottaravādin Tradition. In: Indological and Buddhist Studies. Volume in Honour of Professor J.W. de Jong on his Sixtieth Birthday. Canberra 1982, p. 225-227). Zu einem weiteren Zitat aus dem Bodhisattvapițaka dieser Schule siehe P. Skilling, Citations from the Scriptures of the "Eighteen Schools" in the Tarkajvālā. In: BVS 606-607.

14 Kurz informiert über diese (auch Dhammarucika und Uttaravihāravāsin [hierzu vgl. S. Mori, Uttaravihāratṭhakathā and Sārasamāsa. JPTS 12 (1988) 1-47] genannte) Schule EB I/21-28, 67, 77-78. Wesentliches findet sich auch bei Gunawardana 1979: 14-32.

15 Siehe H. Bechert, Notes on the Formation of Buddhist Sects and the Origins of Mahāyāna. In: German Scholars on India. Vol. I. Varanasi 1973, p. 11 (vgl. auch ders. 1957: 332-333). 
gar nur in tibetischer Übersetzung erhalten ist. ${ }^{16} \mathrm{Ob}$ - wie Stache-Rosen (1984: 29-31) und Bechert (Einleitung dazu, p. 9-15 und 1982: 67-68) vermutet haben - das (auch in chinesischer Übersetzung ${ }^{17}$ ['T 1435] vorliegende) Upāliparipṛcchāsūtra die Stelle des Parivāra der Mahāvihāravāsins im Vinayapițaka der Abhayagirivāsins einnahm (s. auch Yuyama 1979: 45), ist mehr als fraglich, ${ }^{18}$ weshalb auch $H$. Bechert, The Nikāyas of Mediaeval Sri Lanka and the Unification of the Sangha by Parākramabāhu I. In: Studies on Buddhism in Honour of Professor A. K. Warder. Toronto 1993, p. 14, von dieser Annahme abgerückt ist. ${ }^{19}$

An nachkanonischen Werken dieser Schule kennen wir eine im Dīpavamsa verarbeitete Chronik des ceylonesischen Buddhismus, ${ }^{20}$ einen in die Mahāvaṃsațīkā eingeflossenen Mahāvaṃsa-Kommentar (s. von Hinüber 1996: § 188), das Saddhammopāyana (s. von Hinüber 1996: 439, Gunawardana 1979: 22 und Bechert 1998: 4), den nurmehr in (vollständiger) chinesischer und (unvollständiger) tibetischer Übersetzung erhaltenen Vimuttimagga ${ }^{21}$ und u. U. den der chinesischen Übersetzung

${ }^{16} \mathrm{Zu}$ (a) - tena hi bhikkhave mettiyam bhikkhunim sakkāya paṭiñāya nāsetha (zitiert Sp 583,9-10 Vin III 162,38) - s. O. von Hinüber, Buddhist Law According to the Theravāda-Vinaya. A Survey of Theory and Practice. JIABS 18 (1995) 37-38 bzw. 20 (1997) 89, und ders. 1996: § 43, zu (b) P. Skilling, A Citation from the *Buddhavamsa of the Abhayagiri School. JPTS 18 (1993) 165-175, und von Hinüber 1996: 125 .

17 Zu chinesischen Übersetzungen von Texten buddhistischer Kanones sei stellvertretend auf Kōgen Mizuno, Buddhist Sutras. Origin, Development, Transmission. Tokyo 1982, verwiesen.

18 Siehe J.W. de Jong, Review of Stache-Rosen 1984. BSOAS 49 (1984) 591-592, Norman 1993: 208-211 und von Hinüber 1996: 44.

19 Zu Fragmenten des Sanskrit-Textes des Upāliparipṛcchāsūtra s.u. § 4.1.5. An weiterer Sekundärliteratur zu diesem Text seien genannt: V. Stache-Rosen, The Upālipariprechāsūtra. A Vinaya Text in Chinese. In: Buddhism and Jainism, ed. Harish Candra Das et al. Cuttack 1976, p. 24-30, und dies., Das Upāliparipṛcchāsūtra. In: Buddhism in Ceylon and Studies on Religious Syncretism in Buddhist Countries, ed. H. Bechert. Göttingen 1978, p. 58-60, P. Skilling, Une note sur l'Upālipariprecchā. Linh-Son Publication d'Études Bouddhologiques 6 (1979) 19-27, und H. Matsumura, Miscellaneous Notes on the Upālipariprecchāsūtra. AO 51 (1990) 61-109.

20 Siehe E. Frauwallner, Nachgelassene Werke I. Aufsätze, Beiträge, Skizzen. Hrsg. von E. Steinkellner. Wien 1984, p. $20-21$ (unter Verweis auf W. Geiger, Dipavamsa und Mahāvamsa und die geschichtliche Überlieferung in Ceylon. Leipzig 1905, p. $54 \mathrm{ff}$.).

21 Siehe von Hinüber 1996: § 250, P.V. Bapat, Vimuttimagga and Visuddhimagga. A Comparative Study. Poona 1937, p. LI-LIV, Gunawardana 1979: 22-23, Bechert 1982: 68-69, ders. 1998: 4, P. Skilling, Vimuttimagga and Abhayagiri: The Form- 
der Samantapāsādikā zugrundeliegenden Text (s. n. 27), falls denn die deutlichen Abweichungen vom Pāli-Text Buddhaghosas in dieser Weise zu deuten sind (s. H. Bechert, Die Lebenszeit des Buddha. NAWG 1986/4, p. 12). Dass die Gründe, diese Texte den Abhayagiri(vihāra)vāsins zuzuschreiben, auf - zum Teil sehr - schwankendem Boden stehen, macht Norman (1993: 202-217) deutlich. Und so wird z. B. von K. Crosby, History Versus Modern Myth: The Abhayagirivihāra, the Vimuttimagga and Yogãvacara Meditation. JIP 27 (1999) 503-550, nachhaltig bestritten, dass der Vimuttimagga ein Text dieser Schule ist.

\section{DIE JETAVANA(VIHĀRA)VĀSINS}

2. Was eben für die Abhayagiri(vihāra)vāsins gesagt wurde, gilt ähnlich für die Jetavana(vihāra)vāsins - Mahāvaṃsa V 13 Sāgalikas genannt. ${ }^{22}$ Bislang konnte kein Text dieser Schule zugeordnet werden, und wir wissen lediglich, dass sie eine andere Version des Vinayavibhanga als

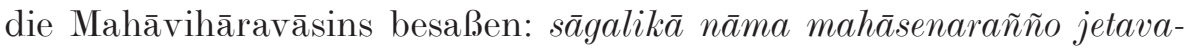

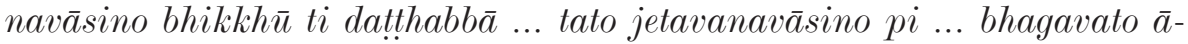
haccabhāsitavinayapitakato ubhatovibhangam gahetvā atthantarapāthan-

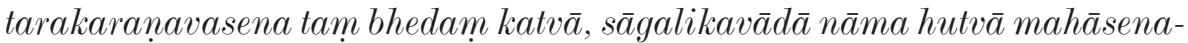
rañña jetavanamhi vihāre kārite vepullam gantvā tattha vasiṃsu, Vạ̣satthappakāsin̄̄ I 175,26-176,10 (hierzu s. Bechert 1982: 69).

\section{Die Dharmaguptakas}

3. Von der für die Verbreitung des Buddhismus nach Zentralasien und China so wichtigen Schule der Dharmaguptakas, die ihre Texte, die denen der Theravādins nahezustehen scheinen, ${ }^{23}$ zunächst in Gāndhārī, später dann in Sanskrit verfaßte, ${ }^{24}$ sind nur sehr wenige Texte in einer indischen Sprache erhalten, und diese zumeist in höchst fragmentarischem Zustand.

\footnotetext{
Aggregate According to the Saṃskṛtāsamskṛta-Viniścaya. JPTS 20 (1994) 171-210, Nakamura 1996: 116, n. 14-16 und T. Hayashi, The Vimuttimagga and Early PostCanonical Literature. Bukkyō Kenkyū (Buddhist Studies) 31 (2003) 91-122.

22. Siehe Bechert 1957: 333-334.

23 Siehe Waldschmidt 1932: 229 und L. Schmithausen, The Problem of the Sentience of Plants in Earliest Buddhism. Tokyo 1991, p. 18.

24 Siehe Waldschmidt 1989: 402-403.
} 
3.1. Der Vinaya ${ }^{25}$ ist in chinesischer Übersetzung (T 1428) überliefert, ${ }^{26}$ und da seit alter Zeit die chinesischen Mönche - und die Mönche solcher Länder, in die der Buddhismus von China aus eingeführt wurde - dem Dharmaguptaka-Vinaya folgen, wurde eine ganze Reihe weiterer Vinaya-Texte ins Chinesische übersetzt (T 1429-1434, 1806-1810). ${ }^{27}$ An Originaltexten dieses Piṭaka sind Teile des Prātimokṣasūtra und des Bhikșuvinayavibhanga erhalten:

3.1.1. Der Dharmaguptaka-Version des Prātimokṣasūtra gehören wahrscheinlich das Fragment SHT I 656, das den Text von Pāt. 65-70 enthält (s. Waldschmidt 1989: 398-401 und Bernhard 1970: 59), ${ }^{28}$ ein kleines Fragment der Sammlung Pelliot (s. von Simson 2000: 153-154) und

25 Zum Vinaya der Dharmaguptakas siehe Frauwallner 1956: 180-182, Hirakawa 1982: 8-9, Lamotte 1988: 169, Prebish 1994: 70-76 und Yuyama 1979: 33-37. Zur chinesischen Übersetzung siehe - außer den genannten Werken - Nakamura 1996: 54-55, Yuyama 1979: 36 und Hu-von Hinüber 1994: 98.

26 Eine Übersetzung der chinesischen Übersetzung des Bhikṣuṇi-Prātimokṣasūtra der Dharmaguptakas (sowie derjenigen der Mahāsānghikas, der Mahīśāsakas, der Sarvāstivādins und der Mūlasarvāstivādins) legte Ch. Kabilsingh, The Bhikkhu$n \bar{\imath}$ Pātimokkha of Six Schools. [Bibliotheca Indo-Buddhica Series 187]. Delhi 1998, vor.

27 Siehe Yuyama 1979: 33-37. Dass Sanghabhadra in seiner chinesischen Übersetzung der Samantapāsādikā diese im Sinne der Dharmaguptakas überarbeitet hat, vermuten P.V. Bapat-A. Hirakawa, Shan-Chien-P'i-P'o-Sha. A Chinese Version by Sanghabhadra of Samantapāsādikā. Poona 1970, p. L-LIII (vgl. auch V. Stache-Rosen, Besprechung von Bapat - Hirakawa, op. cit., in: ZDMG 124 [1974] 210-212, und Bechert in Stache-Rosen 1984: 14). Zu diesem Text siehe auch p. $40 f$.

28 Die Schwierigkeit, den Text des Handschriftenfragments SHT I 44 (zu ergänzen durch V 1071), das erstmals Waldschmidt (1926: 20-37) zugänglich machte (hierzu s. auch Sander 1987: 130-134), dieser Schule zuzuschreiben - wie dies von Hinüber (1985: 59, 66-67, 75) getan hat (s. auch Sander 1991: 140, n. 31) -, liegt in der Anordnung der Regeln (s. Klaus Wille, Zwei kleine Fragmente aus dem Bhikṣuṇīprātimokṣasūtra. In: SWTF-Beiheft 8, p. 308-311; dort ist SHT I 44, um ein weiteres Fragment ergänzt, erneut abgeschrieben). Und so plädiert A. Heirman, On Some Fragments of the Bhikṣuṇiprātimokṣa of the Sarvāstivādins. Buddhist Studies Review 17 (2000) 3-16, (letztlich) für eine Zugehörigkeit zur Schule der Sarvāstivādins. Auch das von Sander (1991: 140) - tentativ - den Dharmaguptakas zugeordnete Fragment SHT I 650, dürfte - worauf mich freundlicherweise mein Göttinger Kollege Dr. Klaus Wille hinweist - nicht dieser Schule, sondern der der Mūlasarvāstivādins zugehören. Denn Sanders zweites, den Ausschlag für die Dharmaguptakas gebendes Argument, das Fragment zeige prakritisches sütam (< skt. sütram), ist falsch; handelt es sich bei diesem Wort doch um das mit su komponierte Verbaladjektiv von $\sqrt{ } u$ "weben", also sütam "wohlgewebt". 
die auf dem Niya-Dokument Nr. 510 erhaltenen Schlußverse 1-7 ${ }^{29}$ (s. Bernhard 1970: 59, Schmithausen 1970: 103, n. 223 und Schmidt 1989: $19 / 38-52)^{30}$ an. $^{31}$

3.1.2. Die zur Sammlung Pelliot gehörenden Bruchstücke des Bhikṣuvinayavibhaṅga wurden herausgegeben von J.-I. Chung - K. Wille, Einige Bhikșuvinayavibhanga-Fragmente der Dharmaguptakas in der Sammlung Pelliot. In: SWTF-Beiheft 8, p. 47-94. ${ }^{32}$

3.2. Von Originaltexten des Sūtrapițaka dieser Schule sind mit Teilen des Sañgīti-, des Mahāparinirvāṇa- und des *Khargaviṣāṇasūtra sowie zweier Versionen des Dharmapada nur mehr geringe Reste erhalten. ${ }^{33}$ Erstgenannter Text ist Teil der von der British Library erworbenen Sammlung von Kharoșthī-Handschriften, ${ }^{34}$ ein Fragment des Mahāparinirvāṇasūtra ist mit SHT III 1024 erhalten $^{35}$ - vielleicht jedoch gehören auch Fragmente des Mahāparinirvāṇasūtra der Schøyen Collection zum Text der Dharmaguptakas. ${ }^{36}$ Das dem Khaggavisāṇasutta der

29 Die Verse 13-14 sind als Teil des Khotan-Dharmapada (hierzu s.u. p. 44 mit n. 39) überliefert (s. Schmidt 1989: 64-67).

30 D. Boucher, Review of Salomon 1999. Sino-Platonic Papers 98 (2000) 64, macht ganz zu Recht darauf aufmerksam, dass die faktische Evidenz für diese Zuordnung nicht sonderlich stichhaltig ist.

31 Auch das von Chung Se Kimm, Ein chinesisches Fragment des Prātimokṣa aus Turfan. Asia Major 2 (1925) 597-608, veröffentlichte Bruchstück dürfte einen Text dieser Schule enthalten (s. ibid. 600 und Bernhard 1970: 60).

32 Der Bhikṣuṇi-Vinaya der Dharmaguptakas liegt jetzt in der vollständigen Übersetzung von A. Heirman, 'The Discipline in Four Parts': Rules for Nuns according to the Dharmaguptakavinaya. Part I-III. [Buddhist Tradition Series 47-49]. Delhi 2002, vor.

33 Von Hinüber (1985: 75) stellt seine zuvor (1982) erwogene Zuordnung der Upāligathā zu dieser Schule wieder in Frage.

34 Hierzu siehe R. Salomon, A Preliminary Survey of Some Early Buddhist Manuscripts Recently Acquired by the British Library. JAOS 117 (1997) 355, und ders. 1999: 171-174.

35 Siehe Waldschmidt 1989: 232-245 und 401-403. Dass dieses tatsächlich die Dharmaguptaka-Version des Mahāparinirvāṇasūtra bietet, wird allerdings von F. Enomoto, The Formation of the Original Texts of the Chinese Āgamas. Toyo Gakujutsu Kenkyu (Journal of Oriental Studies) 23,1 (1984) 103, und A. Iwamatsu, On the Sectarian Affiliation of the Old Chinese Versions of the Smaller Mahāparinirvānasūtra. JIBS 36,2 (1988) 778-784, in Zweifel gezogen.

36 Siehe M. Allon - R. Salomon, Kharoșthī Fragments of a Gāndhārī Version of the Mahāparinirvāṇasūtra. In: Buddhist Manuscripts, ed. J. Braarvig. Vol. I. Oslo 2000, p. 243-273, und K. Wille, Fragments of the Mahāparinirvāṇasūtra. In: Buddhist Manuscripts, ed. J. Braarvig. Vol. II. Oslo 2002, p. 17. In einer der St. 
Theravādins - Teil ihres Suttanipāta (Sn 35-75) - und der Khaḍgavișāṇagāthā der Mahāsāṅghika-Lokottaravādins (Mahāvastu I 357,5-359, 17) entsprechende *Khargaviṣaṇasutra ${ }^{37}$ wurde von R. Salomon unter dem Titel $A$ Gāndhārī Version of the Rhinoceros Sütra (Seattle - London 2000) veröffentlicht, ${ }^{38}$ der Khotan-Dharmapada ${ }^{39}$ von J. Brough als The Gāndhāri Dharmapada (London 1962) und die zweite Version dieses Textes von T. Lenz unter dem Titel A New Version of the Gāndhāri Dharmapada and a Collection of Previous-Birth Stories. British Library Kharoșthī Fragments $16+25$. Seattle - London 2003. Sind somit nur wenige Originaltexte erhalten, ${ }^{40}$ ist der Dīrghāgama dieser Schule in chinesischer Übersetzung (T 1$)^{41}$ überliefert. ${ }^{42}$ Wie das Sūtrapițaka dieser Schule, das einer Angabe der chinesischen Übersetzung des Vinaya

Petersburger Sammlungen befindet sich ein weiteres, bislang allerdings unveröffentlichtes Kharoșțī-Fragment des Mahāparinirvāṇasūtra (s. Salomon 1999: 59).

37 Die - von einer vollständigen Veröffentlichung einstweilen zurückgestellte - Turfan-Handschrift SHT I 26 soll - eingebettet in Erzählungen von Pratyekabuddhas - Verse des Khaḍgaviṣannasūtra der Sarvāstivādins enthalten (s. D. Schlingloff, Die Meditation unter dem Jambu-Baum. WZKS 31 [1987] 111-112 mit n. 5). Es ist dies die Handschrift, die Teile der Jātakamālā des Sanghasena enthält (Bl. 248-301), deren Herausgabe derzeit Professor Dr. Michael Hahn, Universität Marburg, vorbereitet.

38 Besprochen wurde diese Textausgabe von J.C. Wright, The Gandhari Prakrit Version of the Rhinoceros Sutra. Anusamdhān 18 (2001) 1-15.

39 So sollte nach der Entdeckung der zweiten in Gāndhārī verfaßten Version des Dharmapada dieser Schule das von Brough herausgegebene "Gāndhārī-Dharmapada" genannt werden (s. O. von Hinüber, Das ältere Mittelindisch im Überblick. Wien ${ }^{2} 2001$, p. 60). Zur Schulzugehörigkeit dieses Textes siehe von Hinüber 1985: 74 .

40 Auch nach dem Erscheinen von M. Allon, Three Gāndhārī EkottarikāgamaType Sütras. British Library Kharoșthī Fragments 12 and 14. Seattle - London 2001, harren etliche noch der Herausgabe (s. Salomon 1999: 53-54). Und falls (die) Gāndhārī-Texte der jüngst von Robert Senior erworbenen Sammlung ebenfalls aus der Schule der Dharmaguptakas stammen, wäre etwa auch das Śrāmaṇyaphalasūtra erhalten (hierüber berichtete M. Allon auf der 13. IABS-Tagung in Bangkok).

${ }^{41}$ Dieser Āgama scheint (von Buddhayaśas im Jahre $413 \mathrm{n}$. Chr.) nicht aus dem Sanskrit, sondern aus der Gāndhārī übersetzt worden zu sein (s. J. Brough, The Gāndhārī Dharmapada. London 1962, p. 50-54, und ders., Collected Papers. London 1996, p. 303, sowie S. Karashima, A Study of the Underlying Prakrit of the Chinese Dīrghāgama [Japanisch]. Tokyo 1994; kritisch dazu D. Boucher, Gāndhārī and the Early Chinese Buddhist Translations Reconsidered. JAOS 118 [1998] 472-506).

42 Siehe - zuletzt - Salomon 1999: 173-174. Eine gute Übersicht über diesen und die übrigen Āgamas bieten die beiden āgama-Artikel der EB (I/241-248). 
zufolge aus vier Āgamas und einem Kșudrakapițaka bestand, ${ }^{43}$ ansonsten aussah, ist bislang völlig unklar. ${ }^{4}$

3.3. Mit dem ebenfalls in chinesischer Übersetzung überlieferten Śāriputrābhidharma(-śāstra) ('T 1548) ist uns auch ein AbhidharmaText dieser Schule bekannt. ${ }^{45}$ Da den Angaben des DharmaguptakaVinaya zufolge der Abhidharma der eigenen Schule in fünf Teile gegliedert war und da der Śāriputrābhidharma just diese Gliederung aufweist, könnte hier der maßgebliche Abhidharma-Text dieser Schule erhalten sein. ${ }^{46}$

\section{Die Sarvāstivādins}

4. Die Schule der Sarvāstivādins war besonders stark zunächst in der Gegend von Mathurā, später dann im Nordwesten Indiens vertreten. Und von hier aus gelangten ihr Zugehörende nach Zentralasien, was den Umstand erklärt, dass von dort besonders viele Text(fragment)e stammen (s. Sander 1979).

4.1. Lediglich Teile des Vinaya der Sarvāstivādins sind - in mehr oder minder umfangreichen Fragmenten - im Sanskrit-Original erhalten. Das gesamte Vinayapitaka aber $(\text { T } 1435)^{47}$ sowie verschiedene Einzel-

43 Siehe Lamotte 1988: 151 und 160. Zum Kṣudrakapițaka dieser Schule siehe auch Mizuno 1979: 259-260.

${ }^{44}$ Ch.B. Tripāṭ̂̄, Karmavibhangôpadeśa und Berliner Texte. WZKSO 10 (1966) 215, n. 65, zieht in Erwägung, dass die im Karmavibhañgopadeśa - einem Kommentar zum Mahākarmavibhanga - zitierten Sūtra-Texte dem Kanon der Dharmaguptakas zugehören. Von A. Hirakawa, ER II/513, wird die (von Jñānagupta [587-591/2 n. Chr.] stammende) chinesische Übersetzung einer BuddhaBiographie (Fo-pen-hsing-chi-ching, T 190) den Dharmaguptakas zugeordnet (ebenso von A. Yuyama, Bemerkungen zur Sanskrit-Version des Kacchapa-Jātaka. In: XIX. Deutscher Orientalistentag - Vorträge. [ZDMG-Suppl. III,2]. Wiesbaden 1977, p. 1032, Nakamura 1996: 132 und Salomon 1999: 38 und 174), während H. Nakatani, Remarques sur la transmission des Dharmapada. BEI 2 (1984) 137, darin einen Text der Mahāsānghika-Lokottaravādins sieht.

${ }_{45}$ Zur Schulzugehörigkeit und zum Inhalt dieses Textes siehe A. Bareau, Les origines du Śāriputrābhidharmaśāstra. Muséon 63 (1950) 69-95, E. Frauwallner, Abhidharma-Studien. WZKS 16 (1972) 133-152, Schmithausen 1987: 318 und 378 und L.O. Gómez, ER XIII/78 (vgl. auch EB I/71-72).

${ }^{46} \mathrm{Zu}$ Fragmenten eines verwandten Textes siehe K. Matsuda, Three Fragments Related to the Śāriputra-Abhidharma. In: Buddhist Manuscripts, ed. J. Braarvig. Vol. II. Oslo 2002, p. 239-248.

${ }^{47} \mathrm{Zu}$ diesem Vinaya siehe Frauwallner 1956: 177-179, Hirakawa 1982: 7-8, Lamotte 1988: 168-169, Prebish 1994: 76-84 und Yuyama 1979: 1-11. Verschiedene 
texte (Bhikṣu- und Bhikṣuṇīprātimokṣasūtra [T 1436-1437], BhikṣuKarmavācanā [T 1438-1439]) liegen in chinesischer Übersetzung vor. ${ }^{48}$ Eine detaillierte Konkordanz zwischen T 1435, dem (von Kumārajīva, Punyatrāta und Dharmaruci 404 übersetzten) Shisong-lü und allen derzeit bekannten Sanskrit-Fragmenten des Daśādhyāyavinaya bietet J.-I. Chung, Sanskrit-Fragmente des sogenannten Daśādhyāya-vinaya aus Zentralasien. In: SWTF-Beiheft 9, p. 86-98.

4.1.1. Die Prātimokṣasūtra-Fragmente der Berliner, Pariser und Londoner Handschriftensammlungen wurden herausgegeben von von Simson $(1986 / 2000)^{49}$ und Schmidt (1989). Durch diese beiden Ausgaben ${ }^{50}$ sind alle älteren (Teil-)Editionen überholt.

Die Bruchstücke des Bhikṣunī-Prātimokṣa SHT I 44 (= Waldschmidts $P a)$ und I 539 (= Waldschmidts $P b$ ) wurden von Waldschmidt (1926) ediert. Nachträglich zugeordnete Fragmente veröffentlichte Sander (1987: 130-134). ${ }^{51}$

4.1.2. Ostturkestanische Fragmente des Bhikṣuvinayavibhañga wurden von Rosen (1959) herausgegeben. ${ }^{52}$ Später entdeckte und/oder zugeordnete verzeichnen (u.a.) SHT V-VII. Bruchstücke der Udayana-Legende, die Teil dieses Vibhanga ist, veröffentlichte Waldschmidt (1989: 265$289)$.

der Erzählungen, die sich in dieser Version des Vinayapițaka finden, legte E. Chavannes in seinen Cinq cents contes et apologues extraits du Tripitaka Chinois. Paris 1911, p. 231-269, in Übersetzung vor.

48 Auch Vinaya-Kommentare dieser Schule wurden ins Chinesische übersetzt, so die Sarvāstivādavinayavibhāsā (T 1440) und die Sarvāstivādavinayamātṛ̂ā (T 1441). Hierzu siehe Yuyama 1979: 8-9 (§ 1.15.C.2.k.1/2). Einige Fragmente des Sanskrit-Originals des letztgenannten Textes, den Sh. Clarke, The Mūlasarvāstivāda Vinaya Muktaka. Bukkyō Kenkyū (Buddhist Studies) 30 (2001) 81-107, allerdings den Mūlasarvāstivādins zuordnet, fïnden sich in der Turfan- (SHT V 1039, 1059 [hierzu s. Chung 1998: 323-325], 1063, VIII 1940+1955) und - so vermutet wenigstens Yuyama (1979: 11-12 [§ 1.19.5]) - in der Hoernle-Sammlung (s. Hoernle 1916: 4-16).

${ }^{49}$ Man vergleiche auch die Edition von SHT I 39-40 durch G. von Simson, Eine Prātimokṣasūtra-Handschrift in hybrider Sprache. In: BVS 583-604, und SHT $\mathrm{VIII} / 164$.

${ }^{50} \mathrm{Zu}$ von Simsons Edition vergleiche man die Besprechungen (u.a.) von G.-J. Pinault, BEI 19 (2001) 421-424, die diese vor allem aus Sicht der Tocharistik beleuchtet und diesbezüglich wichtige Bemerkungen macht, und von $O$. von Hinüber, OLZ 98 (2003) 577-583.

${ }_{51} \mathrm{Zu}$ SHT I 44 siehe auch oben p. 42, n. 28.

${ }_{52} \mathrm{Zu}$ dieser Ausgabe vergleiche man die Besprechungen von $\mathrm{H}$. Bechert, OLZ 57 (1962) 521-523, und F. Edgerton, Erasmus 12 (1959) 604-607. 
Mit SHT I 394 (hierzu s. Waldschmidt 1926: 18 und 38-49), V 1358, 1385 und 1047a sind nur spärliche Reste des Bhikṣuṇivinayavibhanga erhalten.

4.1.3. Die Turfan-Fragmente verschiedener Karmavācanā wurden von Härtel (1956) herausgegeben. ${ }^{53}$ Dort sind auch die aus Tunhuang stammenden Karmavācanā-Blätter der Sammlung Stein verwertet, die ursprünglich von L. de La Vallée Poussin, Nouveaux fragments de la collection Stein. JRAS (1913) 846-847, veröffentlicht wurden und die vermutlich den Sarvāstivādins zuzuschreiben sind (s. von Hinüber 1985: 69 und $\mathrm{Hu}$-von Hinüber 1994: 85-88).

4.1.4. Verschiedene Fragmente des Vinayavastu ${ }^{54}$ wurden von J.W. de Jong, Three Sanskrit Fragments of the Vinaya of the Sarvāstivādins. IIJ 31 (1988) 11-16, Waldschmidt 1967: 203-225 55 1989: 201-209 und 302-311, V. Stache-Rosen, Das Haṃsa-Jātaka im Vinaya der Sarvāstivādin. ZDMG 127 (1977) 380-391, J. Boltz - R. Salomon, A New Fragment of the Kathinavastu of the Sarvāstivādavinaya. JAOS 108 (1988) 539-544, J.-I. Chung - K. Wille, Fragmente aus dem Bhaișajyavastu der Sarvāstivādins in der Sammlung Pelliot (Paris). In: SWTF-Beiheft 9, p. 105-127, und K. Wille, A Kučā Fragment of the Upasampadā Section of the Sarvāstivādins. Ibid., p. 70-75, veröffentlicht. Einzelheiten hierzu - soweit vor dem Jahre 1979 erschienen - und weitere Fragmente verzeichnet Yuyama (1979: 9-11). Zu solchen siehe auch SHT V-VII und Hartmann - Wille 1992: 63 und 1997: 182. Zu SHT V 1150 vergleiche man insbesondere Hu-von Hinüber 1994: 78-81 und 83.

4.1.5. Von den "Anhängen" sind lediglich kleine Teile erhalten. Zur Upālipariprechā, von deren Sarvāstivāda-Orginaltext nur wenige Fragmente bewahrt sind (SHT I 553 [s. Rosen 1959: 29-30 und 234-237], 566 [= IV 566], III 937 und V 1038/1053 [hierzu s. Chung 1998: 325-328] sowie Foto 167 der Hoernle-Sammlung ${ }^{56}$ ), die jedoch in einer chinesischen Übersetzung überliefert ist (T 1435), siehe oben p. 40, n. 19; zu

53 Hierzu siehe die Besprechungen von W. Couvreur, IIJ 1 (1957) 315-317, F.-R. Hamm, OLZ 52 (1957) 365-367, und A. Minard, BSL 53,2 (1957/58) 58-59.

${ }_{54} \mathrm{Zu}$ diesem siehe auch Härtel 1956: 130-163.

55 Hierzu siehe auch K. Wille, Die Śroṇakoțīkarṇa-Fragmente der Sammlung Pelliot. In: StIB 293-302.

${ }^{56}$ Hierzu siehe K. Wille, Weitere kleine Saddharmapundarīkasūtra-Fragmente. In: Sūryacandrāya. Essays in Honour of Akira Yuyama on the Occasion of his 65th Birthday. Swisttal-Odendorf 1998, p. 243, n. 10. 
dieser und anderem - wie etwa dem Konzilsbericht (hierzu s. Waldschmidt 1967: 226-237) - vergleiche man Yuyama 1979: 11-12.

4.2. Zum Sūtrapițaka der Sarvāstivādins, dessen Madhyamāgama vollständig in chinesischer, von Gautama Sanghadeva zwischen 397 und $398 \mathrm{n}$. Chr. erstellter Übersetzung (T 26) $)^{57}$ erhalten ist und dessen Ekottarāgama (u.U.) in der chinesischen Teilübersetzung An Shigaos (um 160 n. Chr.) vorliegt, ${ }^{58}$ gehört die weit überwiegende Zahl der aus den Oasen des nördlichen Zweigs der Seidenstraße stammenden SūtraText(fragment)e, ${ }^{59}$ die heutzutage in vier großen Sammlungen vorliegen, einmal den Berliner Handschriften, die man nach einem ihrer Fundorte gemeinhin als Turfan-Texte bezeichnet, sodann den Londoner Handschriften der Sammlung Hoernle ${ }^{60}$ den Pariser Handschriften der Sammlung Pelliot und schließlich den Handschriften in St. Petersburg. ${ }^{61}$ Natürlich müsste die Schulzugehörigkeit eines jeden einzelnen dieser Text(fragment)e separat festgestellt werden, die sich u.a. mittels lexikalisch-stilistischer Kriterien bestimmen läßt, welche jüngere Forschung herausgearbeitet hat: pātayantika- (Sarvāstivādins) vs. pāyattika- (Mūlasarvāstivādins), āttamanas- (Sarv.) vs. āptamanas- (Mūlasarv.),

${ }_{57}$ Siehe F. Enomoto, On the Recensions of the Udānavarga. JIBS 28,2 (1980) 933-931 <55-57>, ders., The Formation of the Original Texts of the Chinese Āgamas. Toyo Gakujutsu Kenkyu 23 (1984) 93-108, ders., On the Formation of the Original Texts of the Chinese Āgamas. Buddhist Studies Review 3 (1986) 19-22, ders., The Affiliation of the Central Asian Sūtra Fragments. Bulletin of the Kachō Junior College 29 (1984) 11-26, und Waldschmidt 1989: 370. Eine Konkordanz zwischen Madhyamāgama und Majjhimanikāya ist Thich Minh Chau, The Chinese Madhyama Āgama and the Pāli Majjhima Nikāya. [Buddhist Tradition Series XV]. Saigon 1964 (Nachdruck: Delhi 1991).

58 Hierzu siehe P. Harrison, The Ekottarikāgama Translations of An Shigao. In: BVS 259-283 (vgl. auch de Jong 1966: 4-5 und Bhikkhu Pasadika, Über die Schulzugehörigkeit der Kanon-Zitate im Abhidharmakośabhāṣya. In: SWHL I/185).

59 Siehe L. Sander, Buddhist Sanskrit Manuscripts from Chinese Turkestan: Eighty Years of Research Work. Prajña Bhāratī 3 (1983) 112, und dies., Early Prakrit and Sanskrit Manuscripts from Xinjiang (Second to Fifth/Sixth Centuries C.E.): Paleography, Literary Evidence, and Their Relation to Buddhist Schools. In: Buddhism Across Boundaries Chinese Buddhism and the Western Regions. Sanchung (Taiwan) 1999, p. 61-106.

${ }^{60}$ Über "Die Hoernle-Fragmente in der Turfan-Sammlung (Berlin)" berichtet K. Wille in: Turfan, Khotan und Dunhuang. Hrsg. von R.E. Emmerick et al. Berlin 1996 , p. 385-408.

${ }^{61}$ Über letztere informieren G. Bongard-Levin - M. Vorobyova-Desyatovskaya, Indian Texts from Central Asia (Leningrad Manuscript Collection). [Bibliographia Philologica Buddhica, Series Minor V]. Tokyo 1986, und die Manuscripta Orientalia der Russischen Akademie der Wissenschaften, die in St. Petersburg erscheinen. 
dhārma- (Sarv.) vs. dharmya- (Mūlasarv.), pariṣad- (Sarv.) vs. parṣad(Mūlasarv.), tenopajagāma (etc.) upetya (Sarv.) vs. tenopasamkrāntah (etc.) upasamkramya (Mūlasarv., aber auch Sarv.-Vinaya). ${ }^{62}$ Doch nicht einmal die bislang erarbeiteten Kriterien erlauben eine zweifelsfreie Zuordnung zu einer bestimmten Schule, sieht man einmal ganz davon ab, dass diese zum Teil gar nicht auf die Texte angewandt werden können, da die erhaltenen Fragmente das/die betreffende Wort/Phrase einfach nicht aufweisen. ${ }^{63}$ Deshalb sind im folgenden Text(fragment)e den Sarvāstivādins zugeordnet, wenn ihre geographische Herkunft für und sonst nichts gegen eine solche Zuweisung spricht. Im Sanskrit-Original sind Fragmente (u.a.) der folgenden Sūtras erhalten: ${ }^{64}$

\subsubsection{Vom Dīrghāgama}

- Apaṇakasūtra (SHT III 966, VI 1261, 1579, Sammlung Hoernle [s. Hartmann - Wille 1992: 46] und Pelliot [s. Hartmann - Wille 1997: 141])

- Ambāșțasūtra (SHT III 885, 978, V 1290c, ${ }^{65}$ 1351, 4314 [s. Hartmann 1989: 61-67])

- Arthavistaradharmaparyāya ([u.a.] SHT I 168, 177, 186, III 866b-c, V 1136a, VII 1654, 1699, VIII 1875, Sammlung Hoernle [s. Hartmann 1989: 41-46」) $)^{66}$

- Āṭānāṭikasūtra (s. Hoernle 1916: 24-27 und Hoffmann 1939 ${ }^{67}$ [Nachdruck mit Nachträgen von L. Sander in Sander 1987: 7-121 und $193-208])^{68}$

${ }^{62}$ Siehe vor allem G. von Simson, Stil und Schulzugehörigkeit buddhistischer Sanskrittexte. In: SWHL I/76-93, Sander 1985 und von Hinüber 1985.

${ }^{63}$ Auch muss damit gerechnet werden, dass die zur Rekonstruktion eines Textes verwendeten Fragmente durchaus aus verschiedenen Schulen stammen können (s. O. von Hinüber, Sprachentwicklung und Kulturgeschichte. [AAWL 1992/6]. Stuttgart 1992, p. 67$)$

${ }^{64}$ Im Übrigen vergleiche man zu jedem der Abschnitte 4.2.1-5 die jeweilige "Übersicht über die Handschriften" in den einzelnen $S H T$-Bänden.

${ }_{65}$ Zum uddāna dieses Fragments siehe Hartmann 2002: 142.

${ }_{66} \mathrm{Zu}$ diesem Text siehe auch Hartmann 1999: 129-130 und 134-135, zu seiner tibetischen Übersetzung ders., Notes on Two Texts in the Phug brag Kanjur. In: Suhrllekhāh. Festgabe für Helmut Eimer. [Indica et Tibetica 28]. Swisttal-Odendorf 1996, p. 70-71.

${ }_{67}$ Besprochen wurde diese Textausgabe von E. Waldschmidt, OLZ 43 (1940) 384-387.

68 Sanders Nachträge basieren zwar ausschließlich auf SHT I-V, doch verzeichnen die seitdem erschienenen Kataloge VI-VIII keine weiteren Textfragmente 
- Kūṭatāṇdyasūtra (SHT III 978, V 1290b-c, Sammlung Hoernle [s. Hartmann - Wille 1992: 44] und Pelliot [s. Hartmann - Wille 1997: 143 ])

- *Cańkīsūtra (SHT III 883, IV 165, Sammlung Pelliot [s. Hartmann - Wille 1997: 137])

- Catuṣparișatsūtra (s. E. Waldschmidt ${ }^{69}$ Das Catusparișatsūtra. Teil I-III. Berlin 1952-1962, ${ }^{70}$ Couvreur 1967: 167-168, B. Pauly, Fragments Sanskrits de Haute Asie. JA 247 [1959] 203-226, T. Fukita, Gōma jōdō to gōma. In: Bukkyō bunka no kichō to tenkai (Festschrift Z. Ishigami). Tokyo 2001, I/203-218, und Hartmann - Wille 1992: 59)

- Daśottarasūtra (siehe Mittal 1962,71 D. Schlingloff, Dogmatische Begriffsreihen im älteren Buddhimus. Berlin 1962,72 B. Pauly, Fragments Sanskrits de Haute Asie. JA 245 [1957] 281-292 und 247 [1959] 248-249, Ch. Tripathi, Die Einleitung des Daśottarasūtra. In: Mélanges offerts à Mgr Étienne Lamotte. Louvain 1980, p. 353-358, Sh. Hori, Notes on the Unidentified Sanskrit Fragments in the Ötani Collection at Ryūkoku University Library. JICABS 6 [2003] 103104, und de Jong 1966: 3-25 und 1968: 397-3987) ${ }^{73}$

- *Bodharājakumārasūtra (SHT III 997, IV 33 [Fragm. 23/35], 165, 180, VI 1361, 1373a, Sammlung Hoernle [s. Hartmann - Wille 1992: 29] und Berezovsky [s. G. Bongard-Levin - M.I. Vorob'eva-Desjatovskaja, New Fragments from the Hīnayāna Sūtras. The Bodharājakumāra-sūtra. In: Pamjatniki indijskoj pis'mennosti iz central'noj Azii. Vypusk 2. Moskau 1990, p. 245-249 (= [engl. Version] G. Bon-

mehr. Zu Bruchstücken der Sammlungen Hoernle und Pelliot siehe Hartmann Wille 1992: 44 und 45 bzw. Hartmann - Wille 1997: 137 und 141.

69 Besprechungen der Arbeiten von Waldschmidt sind vollständig verzeichnet in Waldschmidt 1989: XXII-XXIV. Sie werden deshalb hier nicht eigens aufgeführt.

70 Eine "Vergleichende Analyse des Catuṣpariṣatsūtra" legte Waldschmidt (1967: 164-222) vor.

${ }^{71} \mathrm{Zu}$ dem ins Daśottarasūtra aufgenommenen *Cakrasūtra siehe P. Skilling, Sources for the Study of the Mangala- and Mora-suttas. JPTS 24 (1998) 190. Dort handelt der Verfasser auch von einem Gegenstück dieses Sūtra im Saṃskṛtāsaṃskṛtaviniścaya der Sāmmitīyas.

${ }^{72}$ Mittals und Schlingloffs Textausgaben wurden besprochen von J.W. de Jong, IIJ $10(1967 / 68)$ 197-198.

${ }^{73} \mathrm{Zu}$ Fragmenten der Sammlungen Hoernle und Pelliot siehe Hartmann - Wille 1992: 59 bzw. Hartmann - Wille 1997: 179. 
gard-Levin, Three New Fragments of the Bodharājakumārasūtra from Eastern Turkestan. JAOS 109 [1989] 509-512)]) $)^{74}$

- Brahmajālasūtra (SHT III 803, V 1571, VI 1248, 1356, 4189, Sammlung Hoernle [s. Hartmann 1989: 46-57] und Pelliot [s. Hartmann - Wille 1997: 178])

- Bhārgava/Śalyasūtra (SHT I/IV 32, 165, 500, III 992, Sammlung Hoernle [s. Hartmann - Wille 1992: 37, 40 und 47] und Pelliot [s. Hartmann - Wille 1997: 137])

- Mahāgovindasūtra (s. K. Hahlweg, Das Mahāgovinda-Sūtra. München [Inaug.-Diss.] 1954, und D. Schlingloff, Zum Mahāgovindasūtra. MIO $8[1963] 32-50)^{75}$

- Mahāparinirvāṇasūtra (MPS) mit Einschluß des Mahāsudarśanasūtra = MPS, Vorgang 34 (s. E. Waldschmidt, Das Mahāparinirvānasūtra. Teil I-III. Berlin 1950-1951, ders. 1967: 120-163, ${ }^{76}$ Couvreur 1967: 168-169 und 171-172, G. Bongard-Levin-M.I. Vorob'eva-Desjatovskaja, New Fragments from the Hīnayāna Sūtras. The Mahāvadānasūtra and the Mahāparinirvāna-sūtra. In: Pamjatniki indijskoj pis'mennosti iz central'noj Azii. Vypusk 2. Moskau 1990, p. 208-244, J.-U. Hartmann, Der Buddha über die vier Arten von Asketen. Ein Beitrag zum Text des Mahāparinirvāṇasūtra. In: StIB 131-150, K. Wille, Fragments from the Mahāparinirvāṇasūtra. In: Buddhist Manuscripts, ed. J. Braarvig. Vol. II. Oslo 2002, p. 19-20, ${ }^{77}$ Matsumura 1988 und ders., Marginalia to the Sanskrit Fragments of Some Buddhist Texts. Central Asiatic Journal 37 [1993] 121-123) ${ }^{78}$

74 Zur Frage, welchem Āgama dieses Sūtra angehört (haben könnte), vergleiche man Hartmann 1998: 352.

$75 \mathrm{Zu}$ den Fragmenten der Sammlungen Hoernle und Pelliot siehe Hartmann - Wille 1992: 37 und 44 bzw. Hartmann - Wille 1997: 143.

${ }^{76}$ In seinen ursprünglich $N A W G$ (1948) 48-91 bzw. (1961) 375-385 erschienenen Beiträgen "Wunderkräfte des Buddha" bzw. "Der Buddha preist die Verehrungswürdigkeit seiner Reliquien” veröffentlichte Waldschmidt die Vorgänge 31 und 25 des MPS, die er in seiner Gesamtedition des Textes ausgespart hatte. Vorgang 9 der Waldschmidtschen Edition bildet das Giñjakāvasathasūtra. Zu diesem siehe N. Hosoda, Sanskrit Fragments (SHT IV Kat.-Nr. 162) from the Mārgavarga of the Samyuktāgama. Hokkaido Journal of Indological and Buddhist Studies 16 (2001) 30.

77 Dr. Klaus Wille arbeitet derzeit im Rahmen eines in Göttingen angesiedelten DFG-Projektes an einer neuen Gesamtedition des Mahāparinirvāṇasūtra.

78 Eine verbesserte Lesung des von Matsumura publizierten Fragments SHT II 399 findet sich SHT VII/251-252. Zu einem weiteren Fragment eben dieser Handschrift siehe T. Fukita, Soreyue ima Ananda yo. In: Festschrift K. Kagawa. Teil I. Kyoto 2001, p. 160-161. 
- Mahāvadānasūtra (s. E. Waldschmidt, Das Mahāvadānasūtra. Teil I-II. Berlin 1953-1956, und T. Fukita, The Mahāvadānasūtra. A New Edition Based on Manuscripts Discovered in Northern Turkestan. [SWTF-Beiheft 10]. Göttingen 2003).

- Mahāsamājasūtra (s. Waldschmidt 1932: 148-206 und 1989: 382-396 [= Sander 1987: 165-179], Sander 1987: 159-164 und Sammlung Pelliot [s. Hartmann - Wille 1997: 179])

- Māyājālasūtra (SHT IV 33, 165, III 883, V 1025, ${ }^{79}$ Sammlung Hoernle [s. Hartmann - Wille 1992: 44 mit n. 91])

- Śṇatāṇdyasūtra (SHT V 1251, 1352c, Sammlung Hoernle [s. Hartmann 1989: 57-61])

- Śāmaṇyaphalasūtra (SHT V 1290a [s. Sander 1985: 151-153])

- Saṅgītisūtra (s. Hoernle 1916: 16-24, ${ }^{80}$ Stache-Rosen 1968, ${ }^{81}$ Waldschmidt 1967: 258-278, Sammlung Hoernle [s. Hartmann - Wille 1992: 60] und Pelliot [s. Hartmann - Wille 1997: 180]).

Obwohl somit eine stattliche Anzahl von Sūtras dieses Āgama erhalten ist, ist vorläufig noch unklar, welche Sūtras er genau enthalten hat und in welcher Reihenfolge diese angeordnet waren. Wir wissen lediglich, dass das Śnonatāṇdya-, das Kūṭatāṇdya- und das Ambāștasūtra aufeinander folgten ${ }^{82}$ und dass Daśottara-, Arthavistara(dharmaparyāya)-, Sañgīti-, Catuṣpariṣat-, Mahāvadāna- und Mahāparinirvāṇasūtra (inkl. Mahāsudarśanasūtra) den (sog.) Șațsūtraka-Abschnitt bildeten. ${ }^{83}$ Sollte

79 Genauere Angaben, um welche Teilfragmente es sich handelt, entnehme man SHT VII/308 (vgl. auch A. Iwamatsu, A Hitherto Unidentified Sanskrit Āgama Fragment in the SHT. JIBS 38,1 [1989] 415-411, ders., A Supplementary Comment on SHT Cat. Nos. 32, 33. In: Fs. J. Imanishi. Tokyo 1996, p. 241-255, Hartmann - Wille 1992: 44 mit n. 91 und Hartmann 1999: 127).

${ }^{80}$ Hierzu vergleiche man F. Weller, Bemerkungen zu Hoernles Ausgabe der zentralasiatischen Fragmente des Samgītisuttanta. Asia Major 4 (1927) 444-445, der (u.a.) ein Uddāna herstellt.

${ }^{81}$ Diese Textausgabe wurde von J.W. de Jong, OLZ 69 (1974) 84 (= de Jong 1979: 275-277), und H. Bechert, DLZ 93 (1972) 608-610, besprochen.

82 Siehe Sander 1985: 144-145 und Hartmann 1989: 40.

83 Hierzu vorläufig J.-U. Hartmann, Der Șațsūtraka-Abschnitt des in Ostturkistan überlieferten D̄̄rghāgama. In: XXV. Deutscher Orientalistentag - Vorträge. [ZDMG-Suppl. X]. Stuttgart 1994, p. 324-334, und ders. 1999: 127-136. Einzelheiten werden in der noch unveröffentlichten Göttinger Habilitationsschrift von Herrn Hartmann, Untersuchungen zum Dīrghāgama der Sarvāstivādins (1992), zu finden sein. Dort sind auch - nach Auskunft der verschiedenen SHT-Kataloge Fragmente hier nicht verzeichneter Sūtras - wie des Janarșabha-, des Kaivarta-, 
aber der Dīrghāgama der Sarvāstivādins in seinem Aufbau (mehr oder weniger) identisch gewesen sein mit dem der Mūlasarvāstivādins, ${ }^{84}$ wüssten wir über ihn genau Bescheid (s. u. p. 66f.).

4.2.2. Vom Samyuktāgama sind Fragmente (u.a.) folgender Sūtras im Sanskrit-Original erhalten:

- Upasenasūtra (s. Waldschmidt 1967: 329-346 und 368-370, Schmithausen 1997: 11-15 und Sammlung Hoernle [s. Hartmann - Wille 1992: 48$])^{85}$

- Gandhasūtra (s. Waldschmidt 1989: 245-252 und 254)

- Candrasūtra (s. Waldschmidt 1989: 296-301, Enomoto 1994: 3 und K. Wille, Neue Fragmente des Candrasūtra. In: Festschrift Vogel [in Vorbereitung])

- (das zum *Nidānasamyukta [s.u.] gehörende) Daśabalasūtra II ${ }^{86}$ (s. Waldschmidt 1967: 352-357 und 360-361)

- Dhvajāgrasūtra (s. Waldschmidt 1932: 43-53 und 1967: 378-388, Sammlung Hoernle [s. Hartmann - Wille 1992: 36] und Pelliot [s. Hartmann - Wille 1997: 179])

- Nagaropamasūtra (s. G. Bongard-Levin etal., The Nagaropamasūtra. An Apotropaic Text from the Samyuktāgama. In: SWTF-Beiheft 6 , p. 7-131)

- verschiedene Sūtras des *Nidānasaṃyukta (s. Waldschmidt 1967: 288317/318-328 und 1989: 156-172, Ch. Tripathi, Fünfundzwanzig Sūtras des Nidānasamyukta. Berlin 1962, ${ }^{87}$ und de Jong 1979: 237-249)

des Kaśyapasiṃhanāda-, des Mahalli-, des Pañcatraya-, des Prasādanīya- und des Śukasūtra - bearbeitet.

84 Wovon Prof. Hartmann ausgeht, wie er mir freundlicherweise mitteilt.

85 Auch ein in uigurischer Schrift überlieferter Text bietet Teile des SanskritTextes des Upasenasūtra (s. P. Zieme, Indischer Schlangenzauber in uigurischer Überlieferung. In: Tibetan and Buddhist Studies Commemorating the 200th Anniversary of the Birth of Alexander Csoma de Kőrös, ed. L. Ligeti. Budapest 1984, II $/ 425-440)$.

86 Im Unterschied zu dem dem Madhyamāgama zugehörenden Daśabalasūtra I (s.u. § 4.2.3) wird dieses Sūtra des Saṃyuktāgama als Daśabalasūtra II bezeichnet (s. Waldschmidt 1967: 352).

${ }^{87}$ Hierzu vergleiche man die Besprechungen von H. Bechert, DLZ 87 (1966) 21-22, und J.W. de Jong, IIJ 10 (1967/68) 198-199. Eine Textverbesserung bietet W. Couvreur, Zu einigen Sanskrit-Kutschischen Listen von Stichwörtern aus dem Catuṣpariṣatsūtra, Daśottarasūtra und Nidānasūtra. In: Pratidānam. Indian, Iranian and Indo-European Studies Presented to Franciscus Bernardus Jacobus Kuiper. The Hague - Paris 1968, p. 281. 
- Pravāraṇāsūtra (s. Hoernle 1916: 36-40)

- Prahānasūtra (SHT V $1445+1447$ [s. N. Hosoda, A Study on the Mārgavarga of the Samyuktāgama. Tohogaku 105 (2003) 1-16])

- Vātsyasūtra (s. N. Hosoda, The Vatsagotra-Samyukta of the Samyuktāgama. JIBS 43,1 [1994」200-204)

- Veṇukātyāyanasagotrīsūtra (s. Waldschmidt 1989: 362-369)

- *Haimavatasūtra (SHT IV 50 [s. F. Enomoto, On Nos. 1299 and 1329 of the Chinese Version of the Samyuktāgama. JIBS 30,2 (1982) 960-958<82-84>, und Schmithausen 1987: 307-312]).

Auch die als erste "Turfan-Handschriften" veröffentlichten Fragmente SHT I $612+$ V 1174 (s. R. Pischel, [Neue] Bruchstücke des Sanskritkanons der Buddhisten aus Idykutšari, Chinesisch-Turkestān. SBAW 1904, p. 807-827 und 1138-1145) enthalten - wie bereits S. Lévi, Le Samyuktâgama Sanscrit et les Feuillets Grünwedel. T'oung pao 5 (1904) 297-309, zeigen konnte ${ }^{89}$ - mit (u.a.) dem Kokanada-, dem Anāthapiṇdada-, dem Dīrghanakha- und dem Śarabhasūtra Texte aus dem Saṃyuktāgama der Sarvāstivādins. Eine Neuausgabe besorgte N. Hosoda, A Study of the Xylographic Fragments of the Samyuktāgama from Chinese Turkestan, published by R. Pischel. JIBS 37,2 (1989) 540546, ders., Sanskrit Fragments from the Parivrājakasamyukta of the Samyuktāgama (I). In: Indian Philosophy and Buddhism. Essays in Honour of Professor Kotatsu Fujita on His Sixtieth Birthday. Kyoto 1989, p. 185-206, ders., Sanskrit Fragments from the Parivrājakasamyukta of the Samyuktāgama (II)/(III). Hokkaido Journal of Indological and Buddhist Studies 4 (1989) 140-153 und 6 (1991) 172-191.90

$\mathrm{Zu}$ kleineren zum Samyuktāgama gehörenden Textfragmenten siehe Waldschmidt 1989: 210-216 und 252-255 und vor allem F. Enomoto, Sanskrit Fragments Relating to the Samyukta-āgama-sūtra. Bukkyō Kenkyū (Buddhist Studies) 15 (1985) 81-93, und ders. 1994.

4.2.3. Im Sanskrit-Original sind von folgenden Texten des Madhyamāgama Fragmente erhalten:

${ }^{8} 8 \mathrm{Zu}$ Parallelen und Übersetzungen siehe K. Matsuda, A Mahāyāna Version of the Pravāranāsūtra. In: Buddhist Manuscripts, ed. J. Braarvig. Vol. I. Oslo 2000, p. 77, n. 1 .

${ }^{89}$ Hierzu vergleiche auch Oldenberg 1967: II/989-996.

90 Man vergleiche auch dens., Śrenika Parivrājaka in the Samyuktāgama. Hokkaido Journal of Indological and Buddhist Studies 8 (1993) 63-83. 
- (Parallele zum) Aggaññasutta (s. Waldschmidt 1989: 290-295)

- Upālisūtra (s. H. Nakatani, Un fragment xylographique de l'Upālisūtra conservé au Musée Guimet. BEI 4 [1986] 305-319, Hoernle 1916: 27-35, Waldschmidt 1989: 329-345 und von Hinüber 1982 ${ }^{91}$

- Daśabalasūtra I ${ }^{92}$ (s. S. Lévi, Documents de l'Asie Centrale: Textes sanscrits de Touen-Houang. JA [1910] 440-444, und Waldschmidt 1932: 403-421 bzw. 1967: 347-352/362-368 ${ }^{93}$

- Pātalasūtra (s. Waldschmidt 1989: 409-413)

- Mahānidānasūtra (SHT I 581 [s. Waldschmidt 1932: 54-57] und Sammlung Hoernle [s. Hartmann - Wille 1992: 30 und 44]) ${ }^{94}$

- Māratarjanīyasūtra (s. Waldschmidt 1989: 312-319 und ders., Remarks on the Madhyamāgama Ms. Cat.-No. 412. In: SHT IV, Appendix p. 1-5 $)^{95}$

- Rāṣtrapālasūtra (s. Waldschmidt 1989: 346-361 und H. Matsumura, An Aspect of the Development of the Rāṣtrapālasūtra. Bukkyō Kenky $\bar{u}[$ Buddhist Studies] 15 [1985] 39-62)

- Sukasūtra (SHT V 1290d/e, VI 1210) ${ }^{96}$

- *Śronaa(-Koṭiviṃśa-)sūtra (s. Waldschmidt 1989: 217-231 und S. Dietz, The Language of the Turfan and Gilgit Buddhist Sanskrit Texts. In: StIB 89-93).

4.2.4. Deutlich weniger Textfragmente sind bislang von Sūtras des Ekottarāgama bekannt geworden:

- SHT I 590 (s. Mittal 1962: 43-44 und 83-97) ${ }^{97}$

- SHT III 952, 974, 975, 1000 (s. Tripathi 1995: 19 und Y. Okubo, A Study of the Sanskrit Fragments of the Ekottara-ägama. JIBS 31,2 $\lfloor 1983\rfloor 869-866<115-118>$ )

${ }_{91}$ Weitere Textfragmente liegen mit SHT VIII 1802 und 1913 vor. Zu diesem Text vergleiche man auch H. Lüders, Daśanāmaka. In: Kleine Schriften. Hrsg. von O. von Hinüber. Wiesbaden 1973, p. 87-88.

${ }_{92} \mathrm{Zu}$ diesem Sūtra vergleiche auch Waldschmidt 1989: 373 mit n. 13.

93 Wiederabgedruckt sind Waldschmidts zuletzt genannte Beiträge in Sander 1987: 179-192. Dort (p. 179 mit n. 1) sind weitere SHT-Fragmente dieses Textes verzeichnet. Zu Fragmenten der Sammlungen Hoernle und Pelliot siehe Hartmann - Wille 1992: 59 und Hartmann - Wille 1997: 179.

${ }_{94} \mathrm{Zu}$ seinem Platz im Madhyamāgama siehe Hartmann 1998: 352.

95 Ein weiteres Textfragment liegt mit SHT V 1424 vor.

96 Zum Text der Mūlasarvāstivādins s.u. § 5.2.3.

${ }_{97}$ Zugeordnet wurde dieses Fragment von J.-U. Hartmann in SHT VII/257. 
- SHT V 1031 (s. Tripathi 1995: 19)

- SHT V 1161 (s. Tripathi 1995: 19 und S. Dietz, Anmerkungen zum buddhistischen Fastentag. In: BVS 65-66)

- SHT VI 1395.

4.2.5. Obwohl auch die Sarvāstivādins "kleinere" Texte besaßen (s.u.), die von den zu dieser Schule gehörenden Gelehrten auch unter dem Titel kṣudraka zitiert werden (s. E. Lamotte, Khuddakanikāya and Kṣudrakapițaka. East and West 7 [1957] 342), scheint ein *Kṣudrakāgama nicht Bestandteil ihres Sūtrapițaka gewesen zu sein - es scheint ein eigenes viertes Piṭaka gebildet zu haben - bzw. gar nicht ausgebildet worden zu $\operatorname{sein}^{98}$ (s. Mayeda 1985: 95, Lamotte 1988: 151-152 und ders., Problems concerning the Minor Canonical Texts. In: Buddhist Studies in Honour of Hammalava Saddhātissa. Nugegoda 1984, p. 152). Folgende solch "kleinerer Texte" sind in Fragmenten erhalten:99

- Arthavargīyāṇi Sūtrāṇi und Pārāyaṇa, die den Kapiteln IV und V des Suttanipāta der Theravādins entsprechen ${ }^{100}$ (s. A.F.R. Hoernle, The Sutta Nipāta in a Sanskrit Version from Eastern Turkestan. $J R A S$ [1916] 709-732; weitere Textfragmente liegen mit SHT IV $50 / 662$ [p. 236-241] und VI 1581-1582 [p. 198-200] vor) ${ }^{101}$

- Udānavarga ${ }^{102}$ (s. F. Bernhard, Udānavarga. Bd. I-II. Göttingen 1965-1968, und Schmithausen 1970) ${ }^{103}$

98 Wäre Zweitgenanntes der Fall, unterschiede dies die Sarvāstivādins von den Theravādins; ist es doch ein charakteristischer Zug der Theravāda-Überlieferung, alle Texte einer Sammlung einzuverleiben (s. von Hinüber 1996: § 98).

99 Verschiedene solcher Kșudraka-Texte wurden auch ins Chinesische übersetzt (s. Ch. Willemen, A Chinese Kșudrakapițaka [T. IV. 203]. Asiatische Studien 46 [1992] 507-515).

100 Hierzu siehe P.V. Bapat, Arthapada-Sūtra. Visva-Bharati Annals 3 (1950) 90-109.

101 Zu SHT VI 1581 vergleiche auch F. Enomoto, Canonical Verses in the Yogāeārabhūmi. In: SWTF-Beiheft 2, p. 23.

102 Er entspricht dem Udāna und dem Dhammapada der Theravādins (s. von Hinüber 1996: § 89). Mit SHT III 922 ist auch das Fragment eines Kommentars $\mathrm{zu}$ diesem Text erhalten.

${ }_{103}$ Schmithausen konnte zeigen, dass von den beiden (späten) Rezensionen, in denen der Udānavarga vorliegt, die eine (Rez. 1) die der ostturkestanischen Sarvāstivādins, die andere (Rez. 2) die der Mūlasarvāstivādins ist (s. auch F. Enomoto, On the Recensions of the Udānavarga. JIBS 28,2 [1980] 933-931 $<55-57>)$. 
- Sthaviragāthā (s. Bechert 1961: 43-46 und 260-264) ${ }^{104}$

- Anavataptagāthā (s. Bechert 1961 ${ }^{105}$ und H. Matsumura, Pream-

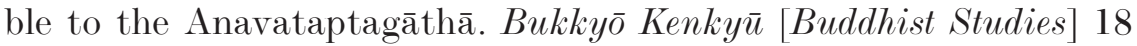

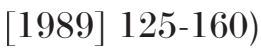

- Preta- und Vimānāvadāna (s. Bechert 1961: 60-61 und 264, ders., On a Fragment of Vimānāvadāna, a Canonical Buddhist Sanskrit Work. In: Buddhist Studies in Honour of I. B. Horner. Dordrecht 1974, p. 19-25, und SHT IV/225-233)

- weitere Avadāna-Texte, u.a. das Cūḍapanthakāvadāna (SHT V 1349, 1464, 1516), das Nāgakumārāvadāna (SHT V 1030 [s. K. Wille, A Turfan Fragment of the Nāgakumārāvadāna. In: SWTF-Beiheft 9, p. 65-69]), das Mandhātāvadāna (SHT IV 558, V 1162), ${ }^{106}$ das Virūpāvadāna (SHT V 1186 [s. Waldschmidt 1989: 414-431]), das Śroṇakoṭīkarṇāvadāna (SHT I 591 [s. Waldschmidt 1967: 203-225] und Sammlung Pelliot [s. K. Wille, Die Śronakoțīkarṇa-Fragmente der Sammlung Pelliot. In: StIB 293-302]) sowie das Siṃhalāvadāna (SHT V 1425 [s. J.-U. Hartmann, Endangered by Man-eating Witches. In: Papers in Honour of Prof. Dr. Ji Xianlin. Peking 1991, II/563$575\rfloor)$.

4.3. Das Abhidharmapițaka dieser Schule bestand - so Abhidharmakośavyākhyā (ed. U. Wogihara) 9,13-14 und 11,25-29 - aus sieben Werken, ${ }^{107}$ die mit Ausnahme des Prajñaptiśāstra ${ }^{108}$ vollständig nur in

104 Sthaviragāthā und Anavataptagāthā wurden von den Mūlasarvāstivādins in ihren Vinaya eingegliedert und sind (fragmentarisch) als Teil des Vinayavastu in den Gilgit-Handschriften erhalten (s. § 5.2.5).

105 Besprochen wurde dieses Werk von F. Bernhard, OLZ 59 (1964) 185-188, und J.W. de Jong, IIJ 7 (1963/1964) 232-235.

106 Dieses Avadāna findet sich auch - in der Version der Mūlasarvāstivādins - als Bestandteil des Divyāvadāna (XVII). Dessen Rahmen bildet dort das Mahāparinirvānasūtra (s. p. 70).

${ }_{107}$ Ausführlich zu diesen L. de La Vallée Poussin, Abhidharmakośabhāṣyam. English Translation by Leo M. Pruden. Berkeley 1988. Vol. I, p. XXIX-LXII (von Pruden) und 1-53 (von de La Vallée Poussin), E. Frauwallner, Abhidharma-Studien II. Die kanonischen Abhidharma-Werke. WZKSO 7 (1964) 59-99, Lamotte 1970: XIX-XXII, EB I/68-71 und Cox 1998: 138-229. Siehe auch H. Sakurabe, Abhidharma. In: Buddhist Spirituality, ed. T. Yoshinori. New York 1995, p. 67-69.

108 Dieses wurde lediglich zum Teil - nämlich nur die Kārạ̣aprajñapti ins Chinesische übersetzt. Jedoch liegt eine vollständige tibetische Übersetzung vor. 
chinesischer Übersetzung erhalten sind: ${ }^{109}$ (1) das Jñānaprasthāna des Kātyāyanīputra, ${ }^{110}$ (2) das Prakaraṇa des Vasumitra, (3) der Vijñānakāya des Devaśarman, (4) der Dharmaskandha des Śāriputra, (5) Maudgalyāyanas dreiteiliges Prajñaptiśāstra, bestehend aus Lokaprajñapti, Kāranaprajñapti111 und Karmaprajñapti, (6) der Dhātukāya des Pūrṇa und (7) der Sañgītiparyāya des Mahākauṣthila. All diese Texte waren Grundlage einer regen Kommentatorentätigkeit, die in dem immens umfangreichen Mahāvibhāṣāsás̄stra (ca. 2. Jh. n. Chr.) - formal ein Kommentar zum Jñānaprasthāna - ihren Niederschlag fand. Von diesem Werk besitzen wir nur einige wenige Bruchstücke des Originaltextes, die von F. Enomoto, A Fragment from a Sanskrit Manuscript of the Vibhāsa. JIBS 42,1 (1993) 495-490<52-55> (Jap.) = A Sanskrit Fragment from the Vibhāṣā Discovered in Eastern Turkestan. In: SWTFBeiheft 6, p. 133-143 (Engl.) veröffentlicht worden sind. Doch liegen drei chinesische Übersetzungen vor (T 1545-1547). ${ }^{112}$

4.3.1. Vom Original des Jñānaprasthāna sind nurmehr kleine Bruchstücke erhalten. Eines ist Bestandteil der Sammlung Pelliot und wurde herausgegeben von B. Pauly, Fragments Sanskrits de Haute Asie (Mission Pelliot). JA 248 (1960) 509-519, und P. Demiéville, Un fragment Sanskrit de l'Abhidharma des Sarvāstivādin. JA 249 (1961) 461-475. Die anderen gehören zur Turfan-Sammlung: SHT I 15 (IV 15), ${ }^{113}$ III 809, 823 (hierzu s. L. Schmithausen, Das Jñānaprasthāna-Fragment SHT III 823. In: BVS 559-569, und N. Hosoda, Drstisamyukta of the

109 Dem folgenden Überblick kam sehr zugute, dass mir Frau Dr. Siglinde Dietz freundlicherweise das Skript ihres Vortrags "The Sanskrit Abhidharma Fragments from the Turfan Oasis", gehalten auf der Tagung "Turfan Revisited" (Berlin, September 2002), zugänglich gemacht hat. Dafür sei ihr auch an dieser Stelle herzlich gedankt.

110 Die chinesischen Übersetzungen dieser Traktate schreiben diese zum Teil anderen Verfassern zu (s. Cox 1998: 177, 181, 189 und 206).

111 Eine detaillierte Analyse der tibetischen Übersetzung sowohl des Loka- als auch des Kāraṇaprajñaptiśāstra legte L. de La Vallée Poussin, Vasubandhu et Yaśomitra. Troisème Chapitre de l'Abhidharmakoça. London 1914-1918, p. 295-350, vor.

112 Siehe E. Frauwallner, Abhidharma-Studien V. Der Sarvāstivādah. WZKS 17 (1973) 98, Schmithausen 1987: 314 und F. Bernhard, Zur Entstehung einer Dhāraṇī. ZDMG 117 (1967) 149-151.

${ }_{113} \mathrm{Zu}$ diesem Fragment siehe H. Lüders, Philologica Indica. Göttingen 1940, p. 723-725, D. Schlingloff, Besprechung von SHT I. ZDMG 116 (1966) 419, Y. Ejima, Fragments of a Manuscript of the Abhidharma Discovered in Turfan. Kokuyaku Issaikyō Indo Senjutsubu Geppō 95 (1976) 19-26, sowie SHT IV/319 und VI/209. 
Saṃyuktāgama and Drṣtivarga of the Jñanaprasthāna. Hokkaido Journal of Indological and Buddhist Studies 10 [1995] 106-129), ${ }^{114} \mathrm{~V} 1131$, 1187 (s. SH' VII/286), VII 1684, 1086, 1752, VIII 1813, 1814, 1849, $1921,1982$.

4.3.2. Vom Prakaraṇa (auch: Prakaraṇapādaśāstra) sind nurmehr wenige Primärfragmente vorhanden: SHT I 599, ${ }^{115}$ III 925, V 1318d, VII 1697 (s. Schmithausen 2002), VIII 1866, 1990 (s. Schmithausen 2000). Auch Teile eines Kommentars zu diesem Text (SHT I 19, 20) sowie einige Stücke des mit dem Prakaraṇa verwandten *Pañcavastuka nebst Kommentar (SHT VIII 1808 [s. SHT V/267-269]) sind im Original erhalten (hrsg. von J. Imanishi, Das Pañcavastukam und die Pañcavastukavibhāșā. NAWG 1969/1, und ders., Fragmente des Abhidharmaprakarạ̣abhāṣyam in Text und Übersetzung. $N A W G$ 1975/1).

4.3.3. Vom Vijñānakāya ist mit SHT VIII 1869 bislang lediglich ein Fragment des Sanskrit-Textes bekannt geworden.

4.3.4. Vom Dharmaskandha sind bislang keine Sanskrit-Fragmente bekannt geworden. ${ }^{116}$ Zum Mūlasarvāstivāda-Text des Dharmaskandha s.u. $\$ 5.3$.

4.3.5. Von der Lokaprajñapti sind lediglich die Sanskrit-Fragmente SHT V 1134, 1177, VI 1594b und 1678 (zur Mūlasarvāstivāda-Version s.u. § 5.3), von der Kāraṇaprajñapti die Fragmente SHT V 1194, VI 1515 und VIII $1817^{117}$ und von der Karmaprajñapti das Fragment VII 1760 erhalten.

4.3.6. Vom Dhātukāya sind bislang keine Sanskrit-Fragmente bekannt geworden.

\footnotetext{
114 Hierzu siehe SHT VIII/160-161.

115 Dieses Textfragment wurde - als fälschlicherweise zum Saṅīitisūtra gehörig - von Stache-Rosen (1968: I/37-38 und 208-212) herausgegeben (vgl. SHT IV/338, n. 1). Eine neue Ausgabe legte J. Imanishi, Honruisoku-ron no gembun ni tsuite ("Über den Text des Prakaraṇa"). Hokkaidō-daigaku Bungaku-bu Kiyō (The Annual Report on Cultural Science, Faculty of Letters, Hokkaido University) 25,2/40 (1977) 4-15, vor (s. auch Schmithausen 2000: 482, n. 6).

116 Die chinesische Übersetzung ( $\mathrm{T}$ 1537) stammt aus der Schule der Sarvāstivādins (s. L. Schmithausen, Zur Liste der 57 "kleineren Fehler" in der Ratnāvalī und zum Problem der Schulzugehörigkeit Nāgārjunas. Stıl 11/12 [1986」 208).

117 Herausgegeben von S. Dietz, Sanskrit Fragments of the Abhidharmaśāstra Kāraṇaprajñapti. In: SWTF-Beiheft 8, p. 95-119.
} 
4.3.7. Ein Fragment des Sanskrit-Textes des Saṅgītiparyāya liegt mit SHT I 767 vor (s. Stache-Rosen 1968: I/37 und 207-212). ${ }^{118}$

\section{Die Mūlasarvāstivādins}

5. Obwohl es wiederholt Versuche gab aufzuzeigen, dass die Mūlasarvāstivādins (letztlich) identisch mit den Sarvāstivādins sind (so zuletzt F. Enomoto, "Mūlasarvāstivādin" and "Sarvāstivādin" In: VRK 239$\left.250^{119}\right)$ bzw. dass ihr Textcorpus - ganz oder teilweise - dasselbe ist (so de Jong 1968), ist der Umstand, "that the Mūlasarvāstivādins not only had a Vinayapițaka but also a Sūtra- and a Kṣudrakapițaka peculiar to them" (Schmithausen 1987: 379), ausschlaggebend, ihnen in diesem Überblick einen eigenen Abschnitt zu widmen. Diese rein praktischen Erwägungen sind jedoch nicht als Antwort auf die Frage des Status dieser Schule innerhalb des Buddhismus zu verstehen.

5.1. Der gesamte Vinaya dieser Schule ${ }^{120}$ liegt uns in tibetischer Übersetzung vor, den die - in der Narthang-Edition 13 Bände umfassende - Sektion 'dul-ba "Vinaya" des tibetischen Kanjur'121 enthält. ${ }^{122}$ Teile davon ${ }^{123}$ wurden auch - von Yi-jing ${ }^{124}$ - ins Chinesische (T 1442-

118 Dass der (auch in einer Handschrift aus Bamiyan [s. Lévi 1932: 9-11] sowie in einer vollständigen chinesischen Übersetzung erhaltene) Sañgītiparyāya ein Mūlasarvāstivāda-Text ist, vermutet Ch. Tripathi, Saṅgīti-Sūtra, Nipāta II, und Ekottarāgama-Parallelen. In: SWHL I/191-199 (vgl. Tripathi 1995: 29 und 34). Dort wird obiges Fragment noch unter der Lüders-Nummer "X 680" zitiert.

119 Ursprünglich veröffentlicht wurde dieser Artikel (auf Japanisch) in JIBS 47,1 (1998) 400-392<111-119>.

${ }_{120} \mathrm{Zu}$ diesem Vinaya siehe Frauwallner 1956: 194-198, Hirakawa 1982: 11-12, Lamotte 1988: 170-171, Prebish 1994: 84-113 und Yuyama 1979: 12-33.

121 Unter Umständen gehört der Bhiksunīvinayavibhanga nicht dem Vinaya der Mūlasarvāstivādins an (s. H. Eimer, Zur Reihenfolge der Texte in der Abteilung Vinaya des tibetischen Kanjur. Zentralasiatische Studien 20 [1987] 222).

${ }_{122}$ Das Prātimokṣasūtra wurde herausgegeben und übersetzt von S.Ch. Vidyabhusana, So-sor-thar-pa (khrims). Calcutta 1915, das Pravrajyāvastu (nach Vorarbeiten von F.-R. Hamm) von H. Eimer, Rab tu 'byun ba'i gźi. Die tibetische Übersetzung des Pravrajyāvastu im Vinaya der Mūlasarvāstivādins. Teil I-II. Wiesbaden 1983. Die Erzählstoffe des Mūlasarvāstivāda-Vinaya wurden analysiert auf Grund der tibetischen Übersetzung von Panglung (1981).

123 Vom Vinayavastu beispielsweise wurden lediglich Pravrajyā-, Varșā-, Pravāraṇā-, Carma-, Bhaiṣajya-, Kaṭhiṇa- und Sanghabhedavastu übertragen (s. Wille 1990: 15-16). Und selbst diese Übersetzungen sind zum Teil lückenhaft.

124 Über weitere chinesische Übersetzungen informieren Yuyama (1979: 12-33), Hu-von Hinüber (1994: 96) und Sh. Clarke, The Mūlasarvāstivādin Vinaya. A Brief 
1451) ${ }^{125}$ übersetzt. Doch sind vom Vinaya der Mūlasarvāstivādins beträchtliche Teile auch im Sanskrit-Original erhalten.

5.1.1. Das Prātimokșasūtra ist nach Handschriften aus Gilgit herausgegeben von A.Ch. Banerjee, The Prātimokṣa Sūtra. IHQ 29 (1953) 162-174, 266-275 und 363-377 (= Banerjee 1977: 1-56). Der Schlussteil wurde von Schmidt (1989: 91-94) ${ }^{126}$ und jeweils ein Fragment aus Gilgit von Lokesh Chandra, Unpublished Gilgit Fragment of the PrātimokșaSūtra. WZKSO 4 (1960) 1-13, und Lévi (1932: 20) ediert. ${ }^{127}$ Die Fragmente der Berliner (SHT I 2, 41, 100d und 355) und der Pariser Sammlung bearbeitete von Simson (2000: 150-153). Eine neue Edition des gesamten Prātimokșasūtra - auf Grund der eben genannten Textfragmente und einer vollständigen Handschrift aus Tibet (zwischenzeitlich in Peking gelagert) - ist von Hu-von Hinüber (1994: 53, n. 1 und 77, n. 1) angekündigt. Übersetzt ist das Sūtra von Prebish (1975), wozu man die (kritischen) Besprechungen von J.W. de Jong, IIJ 19 (1977) 127-130 (= de Jong 1979: 305-308), und H. Bechert, JAOS 98 (1978) 203-204, vergleiche.

5.1.2. Auch kleine Bruchstücke des Vinayavibhanga ${ }^{128}$ sind im Original erhalten. Eines, das den Text des Vibhanga zu Pārājika 3 enthält, ist herausgegeben von Rosen (1959: 230-234); weitere verzeichnen Yuyama (1979: 19-20) und die verschiedenen SHT-Kataloge. ${ }^{129}$

5.1.3. Erhaltene Fragmente von Bhikṣukarmavācanā-Texten verzeichnet Yuyama (1979: 17-19). An dieser Stelle seien lediglich die Editionen von $\mathrm{O}$. von Hinüber, Eine Karmavācanā-Sammlung aus Gilgit. ZDMG 119 (1970) 102-132 (wozu man J.-I. Chung, Two karmavācanā Texts of

Reconnaissance Report. In: Early Buddhism and Abhidharma Thought in Honour of Doctor Hajime Sakurabe. Kyoto 2002, p. 45-64.

${ }_{125}$ Die Buddha-Vita dieser zwischen 700 und 712 n. Chr. entstandenen Übersetzung ist auszugsweise übertragen von E. Waldschmidt, Die Legende vom Leben des Buddha. Berlin 1929 (Nachdruck: Graz 1982).

${ }^{126}$ Hierzu siehe die Besprechung von K.R. Norman, Buddhist Studies Review 7 (1990) 125-129.

${ }_{127}$ Weitere bislang nicht veröffentlichte Bruchstücke verzeichnet Yuyama (1979: 13).

128 Klaus Wille verdanke ich den Hinweis, dass eine Handschrift der Rick Adams Collection, Baltimore, große Teile des Textes des Vinayavibhanga enthält.

129 Panglung weist darauf hin, "dass mittels des Divyāvadāna auch Teile des Vinayavibhangga und des Vinayakșudraka" - eine Ergänzung zum Vinayavibhanga sowie zum Vinayavastu - "die nicht in den G(ilgit) M(anuscripts) erhalten sind, als in Sanskrit überliefert betrachtet werden können" (1981: XV). 
the Mūlasarvāstivādins: cūvarādhișthāna and pātrādhișthāna. In: BVS 39-54, vergleiche), und A. Ch. Banerjee, Bhikṣukarmavākyam. IHQ 25 (1949) 19-30 (= Banerjee 1977: 57-73), genannt; zu SHT I 573 siehe Yuyama 1979: 4-5 und Härtel 1956: 49.

Ein Bhikṣun̄īkarmavācanā-Text aus Nepal, der von C.M. Ridding und L. de La Vallée Poussin, A Fragment of the Sanskrit Vinaya. Bhiksunikarmavacana. BSOS 1 (1920) 123-143, herausgegeben wurde, liegt nun in der zuverlässigeren Edition von M. Schmidt, Bhikṣuṇ̄-Karmavācanā. Die Handschrift Sansk. c.25(R) der Bodleian Library Oxford. In: StIB 239-288, vor. Zur Zuordnung zu den Mūlasarvāstivādins siehe M. Schmidt, Zur Schulzugehörigkeit einer nepalesischen Handschrift der Bhikṣun̄ī-Karmavācanā. In: SWTF-Beiheft 5, p. 155-164, und J.-I. Chung, "Bhikșun̄ī-Karmavācanā" of the Mūlasarvāstivādins. In: Facets of Indian Culture. Gustav Roth Felicitation Volume. Patna 1998, p. 420421 (s. auch Hu-von Hinüber 1994: 53, n. 9). Fraglich ist die Schulzugehörigkeit eines zweiten Bhikṣun̄ikarmavācanā-Textes aus Nepal, der von C. Bendall, Fragment of a Buddhist Ordination-Ritual in Sanskrit. In: Album Kern. Leiden 1903, p. 373-376, veröffentlicht wurde (hierzu s. M. Schmidt, a.a.O., p. 161-162, und J.-I. Chung, a.a.O., p. 421, und vgl. Yuyama 1979: 19).

5.1.4. Ein Großteil des Vinayavastu ist im Sanskrit-Original erhalten. Über die erhaltenen Reste informiert umfassend Wille (1990); ${ }^{130}$ des weiteren vergleiche man Yuyama 1979: 24-32. Der Text des Poṣadhavastu der (ursprünglich vermutlich 523 Blätter umfassenden) GilgitHandschrift wurde von $\mathrm{Hu}$-von Hinüber $(1994)^{131}$ herausgegeben - die Sīmā-Regeln dieses Vastu waren Gegenstand einer Studie von KiefferPülz (1992: 361-434) -, der des Pravāranavastu von Chung (1998: 123174), der des Kaṭinavastu von H. Matsumura, The Kathinavastu from the Vinayavastu of the Mūlasarvāstivādins. In: SWTF-Beiheft 6, p. 145239, ${ }^{132}$ der des Pāndulohitakavastu von N. Yamagiwa, Das Pāndulohita-

130 Dort sind auch vorher nicht veröffentlichte Textfragmente ediert. Zu weiteren siehe nun die SHT-Kataloge VII-VIII und K. Matsuda, A Vinaya Fragment of the Mūlasarvāstivādin from 'Bendall's Puka' in the National Archives, Kathmandu. In: BVS 431-437.

131 Hierzu vergleiche man den Besprechungsaufsatz von J.W. de Jong, in: Dharmadūta. Mélanges offerts au Vénérable Thích Huyên-Vi. Paris 1997, p. 163167.

${ }_{132} \mathrm{Zu}$ diesem Vastu vergleiche man auch Kun Chang, A Comparative Study of the Kathinavastu. 's-Gravenhage 1957, p. 51-64, mit den Besprechungen von $\mathrm{H}$. Bechert, ZDMG 110 (1961) 203-205, und F. Weller, IIJ 4 (1960) 306-311. 
kavastu. [Indica et 'Tibetica 41]. Marburg 2001, der des Śayanāsana-, des Adhikarana- und des Sanghabhedavastu von Gnoli 1978 und 1977 (zu letzterem vgl. auch H. Matsumura, Three Notes on the Sanghabhedavastu. I'T 15-16 [1989/1990」233-247). 'Teile des Pravrajyāvastu haben C. Vogel und K. Wille herausgegeben: Some Hitherto Unidentified Fragments of the Pravrajyāvastu Portion of the Vinayavastu Manuscript Found Near Gilgit. NAWG 1984/7, p. 299-337; Some More Fragments of the Pravrajyāvastu Portion of the Vinayavastu Manuscript Found Near Gilgit. In: SWTF-Beiheft 4, p. 65-109; The Final Leaves of the Pravrajyāvastu Portion of the Vinayavastu Manuscript Found Near Gilgit. Part 1. In: SWTF-Beiheft 6, p. 241-296; The Final Leaves of the Pravrajyāvastu Portion of the Vinayavastu Manuscript Found Near Gilgit. Part 2. In: SWTF-Beiheft 9, p. 11-76. "Fragmente aus dem Bhaișajyavastu der Sarvāstivādins in der Sammlung Pelliot (Paris)" haben J.-I Chung und K. Wille in SWTF-Beiheft 9, p. 119-124, veröffentlicht. ${ }^{133}$

5.1.5. Diesem Vinaya gehört auch die Upasampadājñapti zu, zu deren Textausgabe durch B. Jinananda, Upasampadājñaptih. [TSWS VI]. Patna 1961, auf Grundlage einer Handschrift aus dem Kloster Ngor in Tibet (Sammlung Sankrityayana), man H. Sakurabe, The Pravrajyā-

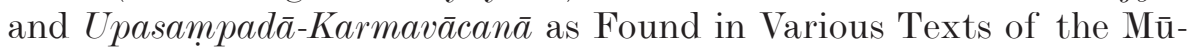
lasarvāstivādin Vinaya. JIBS 12,2 (1964) 496-504, H. Nishino, The Upasampadājñaptị of the Mūlasar[vāsti]vādin Vinaya. JIBS 15,1 (1966) 188-189, und J.-I. Chung, A New Edition of the "Upasampadājñapti" (1). BEI 13/14 (1995/96) 61-72, vergleiche. Und auch das Vinayasūtra des Gunaprabha scheint ein Text dieser Schule zu sein (s. von Hinüber 1985: 68, n. 30). Es wurde in Gänze von Rahula Sankrityayana, Vinayasūtra of Bhadanta Gunaprabha. [Singhi Jain Series 74]. Bombay 1981, sein erstes Kapitel von P.V. Bapat - V.V. Gokhale, Vinaya-Sūtra and Auto-Commentary on the Same. [TSWS 22]. Patna 1982, und der Vinayasūtra Study Group im Annual of the Institute for Comprehensive Studies of Buddhism. Taisho University 25 (2003) 541-492<44-93> (unter dem Titel The Pravrajyāvastu of the Vinayasūtra and its Vrtti [1]), herausgegeben (vgl. auch P.V. Bapat, Guṇaprabha's Vinaya-sūtra and His Own Commentary On the Same. JIABS 1 [1978] 47-51). Verschiedene Abschnitte dieses Textes waren Gegenstand von Arbeiten von M. Nakaga-

133 Es ist wiederum Klaus Wille, dem ich den Hinweis verdanke, dass ein Großteil des Bhaișajyavastu (samt Anavataptagāthā) nun auch in einer Handschrift vorliegt, deren einer Teil sich in der Schøyen-Sammlung, deren anderer Teil sich in der Rick Adams Collection, Baltimore, befindet. 
wa: Vinayasūtravṛtti of Guṇaprabha - Pārājikam (1). Nanto Bukkyō (Journal of the Nanto Society for Buddhist Studies) 25 (1987) 50-69; Vinayasūtravẹtti of Guṇaprabha - Pārājikam (2). Sanskrit Text. In: Essays in Honor of Dr. Shoren Ihara. Fukuoka 1991, p. 251-274; On $a$ brahmacarya-pārājikam in the Vinaya-sūtra. JIBS 34,1 (1985) 398-394 <71-75>; On abrahmacarya-pārājikam in the Vinaya-sūtra (II). JIBS 36,1 (1987) 402-399<80-83>; On abrahmacarya-päräjikam in the Vinayasūtra (III). JIBS 38,2 (1990) 880-877<64-67>; On adattādāna-pārājikam in the Vinayasūtra (I). JIBS 41,2 (1993) 1026-1022<137-141>; The Text of the adattādāna-pārājikam in the Vinayasūtravrtti. Journal of Chikushi Jogakuen Junior College 31 (1996) 19-26; On the Adattādāna-pārājikam in the Vinayasūtravp̣tti, JIBS 48,2 (2000) 1135-1133<18-20>; On adattāāna-pārājikam in the Vinayasūtra (IV). In: Early Buddhism and Abhidharma Thought in Honour of Doctor Hajime Sakurabe. Kyoto 2002, p. 233-240. Wichtige Informationen zu diesem Text bietet die Introduction to the Facsimile Edition of a Collection of Sanskrit Palmleaf Manuscripts in Tibetan dBu med Script. Tokyo 2001; ansonsten siehe Priya Sen Singh, The Vinaya Sūtra of Guṇaprabha. A Historical Note. Buddhist Studies (University of Delhi) 10 (1986) 105-111.

5.2. Bis zur Entdeckung der aus Pakistan stammenden DīrghāgamaHandschrift (s.u.) war wenig von den Originaltexten der vier Āgamas der Mūlasarvāstivādins erhalten. ${ }^{134}$ Und zumeist sind diese als Teil des Vinaya überliefert (den Titeln dieser Texte ist im folgenden ein "†" vorgesetzt). ${ }^{135}$ Doch gehört der vollständige (T 99) und sehr wahrscheinlich auch der unvollständige Saṃyuktāgama (T 100) ${ }^{136}$ dieser Schule

134 Zu Sūtras als Bestandteilen des Divyāvadāna und des Avadānaśataka s.u. p. 70 .

135 Meines Wissens gibt es keine Zusammenstellung, welche Āgama-Sūtras (in welchem Umfang) in dem in den Gilgit-Handschriften erhaltenen Text des Mūlasarvāstivāda-Vinaya zitiert werden; und gleiches gilt für dessen tibetische Übersetzung. Zu Verweisen auf Sūtras aller vier Āgamas im Bhaișajyavastu des Vinayavastu der Gilgit-Handschrift siehe Waldschmidt 1989: 374-378 (vgl. auch de Jong 1968: 398).

${ }^{136}$ Zur Schulzugehörigkeit von T 99 - diese Übersetzung wird Gunabhadra zugeschrieben, der sie zwischen 435 und $443 \mathrm{n}$. Chr. angefertigt haben soll - siehe (u.a.) F. Enomoto, The Formation of the Original Texts of the Chinese Agamas. Toyo Gakujutsu Kenkyu 23 (1984) 93-108, ders., On the Formation of the Original Texts of the Chinese Āgamas. Buddhist Studies Review 3 (1986) 23, Schmithausen 1987: 306 und 377 und S. Hiraoka, The Sectarian Affiliation of Two Chinese Samyuktāgamas. JIBS 49,1 (2000) 506-500<1-7>; zu der von T 100 siehe Wald- 
zu, ${ }^{137}$ aus deren Sūtrapițaka auch die Sūtras stammen, deren Übersetzungen sich in der Sektion Vinaya ('dul ba) des Kanjur finden. Diesem Piṭaka lassen sich auch diejenigen Sūtras zuordnen, die in von Mūlasarvāstivādins verfaßten Lehrtraktaten zitiert werden; an erster Stelle sind hier der Abhidharmakośa samt Kommentaren ${ }^{138}$ und die Yogācārabhūmi zu nennen. ${ }^{139}$

5.2.1. Von folgenden Texten des Dīrghāgama sind größere Teile erhalten:

- †(Parallele zum) Aggaññasutta (s. S. Dietz, The Language of the Turfan and Gilgit Buddhist Sanskrit Texts. In: StIB 85-89)

- †Catuṣpariṣatsūtra (s. E. Waldschmidt, Das Catusparișatsūtra. Teil III. Berlin 1962)

- †Mahāvadānasūtra (s. T. Fukita, On and Around Hybrid Sanskrit in the Mahāvadānasūtra and the Sañghabhedavastu. JIBS 35,1 [1986] $490-488<12-14>$ )

- Mahāsudarśanasūtra ${ }^{140}$ (s. Couvreur 1967: 169-171, H. Matsumura, The Mahāsudarśanāvadāna and the Mahāsudarśanasūtra. Delhi 1988,

schmidt 1989: 380-381, F. Enomoto, On the Recensions of the Udānavarga. JIBS 28,2 (1980) 933-931<55-57>, und Schmithausen 1987: 306 und 377.

${ }_{137} \mathrm{Zu}$ einer weiteren chinesischen Samyuktāgama-Übersetzung (T 101) - u.U. von An Shigao stammend - siehe P. Harrison, Another Addition to the An Shigao Corpus? In: Early Buddhism and Abhidharma Thought in Honour of Doctor Hajime Sakurabe. Kyoto 2002, p. 1-32.

138 Diese Āgama-Zitate wurden systematisch von Bhikkhu Pasadika, Kanonische Zitate im Abhidharmakośabhāșya des Vasubandhu. In: SWTF-Beiheft 1, p. 9-136, und Yoshifumi Honjo, A Table of Agama-Citations in the Abhidharmakosa and Abhidharmakośopāyikā. Part I. Kyoto 1984, gesammelt. Nicht zugänglich war mir Kōtatsu Fujita, 'Kusharon' shoin no Agongyō ichiran ("Conspectus of Āgama Texts in the Abhidharmakośabhāsya"). Sapporo 1984 (zu einem Zitat aus der Sanskrit-Version des Brahmajālasūtra in Yaśomitras Abhidharmakośavyākhyā s. L. de La Vallée Poussin, Pāli and Sanskrit. JRAS [1903] 359-362).

139 Zur Schulzugehörigkeit des erstgenannten Textes s. Schmithausen 1970: 112 mit n. 257, von Hinüber 1985: 68, n. 30, zu der des letzteren Schmithausen 1987: 305, ders., Zur Liste der 57 "kleineren Fehler" in der Ratnāvalī. StII 11/12 (1986) 208, und F. Enomoto, Śarīrārthagāthā: Canonical Verses in the Yogācārabhūmi. In: SWTF-Beiheft 2, p. 21.

140 Auf dieses Sūtra als Bestandteil des Șațsūtranipāta des Dīrghāgama verweist der Mūlasarvāstivāda-Vinaya: vistareṇa mahāsudarśanasūtre dīrghāgame șațsūtrakanipāte (N. Dutt, Gilgit Manuscripts III/1, p. 97,13). 
und ders., Marginalia to the Sanskrit Fragments of Some Buddhist Texts. Central Asiatic Journal 37 [1993] 120-124)

- †Śrāmaṇyaphalasūtra (s. W. Couvreur, Sanskrit-Tochaarse en Sanskrit-Koezsjische Trefwoordenlijsten van de Dīrghāgama [Dīghanikāya]. Orientalia Gandensia 4 [1967] 164, K. Meisig, Das Śrāmanyaphalasūtra. [Freiburger Beiträge zur Indologie 19]. Wiesbaden 1987, G. MacQueen, A Study of The Śrāmanyaphala-sūtra. [H'reiburger Beiträge zur Indologie 21]. Wiesbaden 1988, und P. Ramers, Die 'Drei Kapitel über die Sittlichkeit' im Śrāmanyaphalasūtra. Die Fassungen des Dīghanikāya und Samghabhedavastu, verglichen mit dem Tibetischen und Mongolischen. [Inaug.-Diss.] Bonn 1996). ${ }^{141}$

Nach der Entdeckung und (ersten) Bearbeitung einer aus Pakistan stammenden Dīrghāgama-Handschrift, deren einer Teil zur HirayamaSammlung (Kamakura, Japan), deren anderer Teil zur Rick Adams Collection, Baltimore, gehört, hat sich die Sachlage grundlegend gewandelt. Mit ihr ist nun ein sehr großer Teil des Textes dieses Āgama erhalten, der in den nächsten Jahren ediert werden wird. ${ }^{142}$ Und dieser Handschrift zufolge gestaltet sich der Aufbau des Dīrghāgama der Mūlasarvāstivādins - und damit auch vermutlich der der gleichen Textsammlung der Sarvāstivādins (s.o. p. 52f.) - wie folgt: ${ }^{143}$

\begin{tabular}{|c|c|c|c|c|c|}
\hline $\begin{array}{c}1 . \\
\text { Daśottara }\end{array}$ & $\begin{array}{c}2 . \\
\text { Arthavistara }\end{array}$ & $\begin{array}{c}3 . \\
\text { Sañgīti }\end{array}$ & $\begin{array}{c}4 . \\
\text { Catuṣparișat }\end{array}$ & $\begin{array}{c}5 . \\
\text { Mahāvadāna }\end{array}$ & $\begin{array}{c}6 . \\
\text { Mahāparinirvāṇa }\end{array}$ \\
\hline $\begin{array}{c}\text { Apannaka } \\
\text { Sarveka (?) }\end{array}$ & Bhārgava & Śalya & Bhayabhairava & Romaharșaṇa \\
\hline
\end{tabular}

${ }^{141}$ Siehe auch P.V. Bapat, The Śrāmanyaphala-Sūtra and Its Different Versions in Buddhist Literature. Indian Culture 15 (1948/49) 107-114, und ders., Another Valuable Collection of Buddhist Sanskrit Manuscripts. ABORI 30 (1949) 241-253. Die tibetische Übersetzung dieses Sūtra war Gegenstand einer Untersuchung von C. Vogel: The Teachings of the Six Heretics. [AKM 39]. Wiesbaden 1970.

${ }_{142}$ Vorläufig vergleiche man Hartmann 2000 und 2002 und A. Sadakata, The Gilgit Manuscript: Deciphering the Mahāgovindasūtra Fragment. Daihōrin (1999) $30-35$.

143 Ich möchte Herrn Professor Dr. Hartmann auch an dieser Stelle ganz herzlich dafür danken, dass er mir seinen auf der 13. IABS-Tagung (Bangkok 2002) gehaltenen Vortrag noch vor dessen Veröffentlichung zugänglich gemacht hat. In diesem wurden Namen und Reihenfolge der Sūtras, so wie sie von mir in obiger Tabelle aufgeführt sind, vorgestellt. 


\begin{tabular}{|c|c|c|c|c|c|}
\hline $\begin{array}{c}13 . \\
\text { Jinayabha }\end{array}$ & $\begin{array}{c}14 . \\
\text { Govinda }\end{array}$ & $\begin{array}{c}15 . \\
\text { Prāsādika }\end{array}$ & $\begin{array}{c}16 . \\
\text { Prasādanīya }\end{array}$ & $\begin{array}{c}17 . \\
\text { Pañcatraya }\end{array}$ & $\begin{array}{c}18 . \\
\text { Māyājāla }\end{array}$ \\
\hline $\begin{array}{c}19 . \\
\text { Kāmaṭika }\end{array}$ & $\begin{array}{c}20 . \\
\text { Kāyabhāvanā }\end{array}$ & $\begin{array}{c}21 . \\
\text { Bodha }\end{array}$ & $\begin{array}{c}22 . \\
\text { Śạkara }\end{array}$ & $\begin{array}{c}23 . \\
\text { Āṭānāṭa }\end{array}$ & $\begin{array}{c}24 . \\
\text { Mahāsamāja }\end{array}$ \\
\hline $\begin{array}{c}25 . \\
\text { Tridaṇdin }\end{array}$ & $\begin{array}{c}26 . \\
\text { Piṅgalātreya }\end{array}$ & $\begin{array}{c}27 . \\
\text { Lohitya I }\end{array}$ & $\begin{array}{c}28 . \\
\text { Lohitya II }\end{array}$ & $\begin{array}{c}29 . \\
\text { Kaivartin }\end{array}$ & $\begin{array}{c}30 . \\
\text { Maṇḍīsa I }\end{array}$ \\
\hline $\begin{array}{c}31 . \\
\text { Maṇdịśa II }\end{array}$ & $\begin{array}{c}32 . \\
\text { Mahallin }\end{array}$ & $\begin{array}{c}33 . \\
\text { Śroṇatāṇḍa }\end{array}$ & $\begin{array}{c}34 . \\
\text { Kūṭatāṇḍya }\end{array}$ & $\begin{array}{c}35 . \\
\text { Ambāṣtha }\end{array}$ & $\begin{array}{c}36 . \\
\text { Prọsthapāla }\end{array}$ \\
\hline $\begin{array}{c}37 . \\
\text { Kāraṇavādin }\end{array}$ & $\begin{array}{c}38 . \\
\text { Pudgala }\end{array}$ & $\begin{array}{c}39 . \\
\text { Śruta }\end{array}$ & $\begin{array}{c}40 . \\
\text { Mahalla }\end{array}$ & $\begin{array}{c}41 . \\
\text { Anyatama }\end{array}$ & $\begin{array}{c}42 . \\
\text { Śska }\end{array}$ \\
\hline $\begin{array}{c}43 . \\
\text { Jīvaka }\end{array}$ & $\begin{array}{l}44 . \\
\text { Rāja }\end{array}$ & $\begin{array}{c}45 . \\
\text { Vāsișṭha }\end{array}$ & $\begin{array}{c}46 . \\
\text { Kāśsapa }\end{array}$ & $\begin{array}{c}47 . \\
\text { Brahmajāla }\end{array}$ & \\
\hline
\end{tabular}

Die Sūtras 1 bis 6 bilden den bereits oben genannten Șațūtraka- (s. $\S 4.2 .1$ ), die der Nummern 25 bis 47 den Śīlaskandha-Nipāta (s. Hartmann 2002: 146-147). ${ }^{144}$

5.2.2. Auch einige zum Saṃyuktāgama gehörende Text(fragment)e ${ }^{145}$ sind erhalten:

- SHT I 582 (s. Waldschmidt 1967: 279-287 = [Engl.] 1989: 156-172)

- †Upasenasūtra (s. J.L. Panglung, Zwei Beschwörungsformeln gegen Schlangenbiss im Mūlasarvāstivādin-Vinaya und ihr Fortleben in der Mahāmāyūrīvidyārājñ̄i. In: Festschrift für Günther Klinge zum 70. Geburtstag. Wiesbaden 1980, p. 66-71, und Schmithausen 1997: 11, n. 7)

- Śronasūtra (s. L. de La Vallée Poussin, MSS. Cecil Bendall. JRAS [1907] 375-379)

- Devatā- und Alpadevatāsūtra (s. A. Mette, Zwei kleine Fragmente aus Gilgit. StII 7 [1981] 139-151, F. Enomoto, On the *Devatāsamyukta

${ }^{144}$ Zu diesen beiden Nipātas siehe auch P. Skilling, The Daśottara-Sūtra, the Sațūtraka-Nipāta, and the Śīlaskandhikā. Linh-Son Publication d'Études Bouddhologiques 10 (1980) 26-35.

145 Verschiedene kleinere Bruchstücke aus Sūtras des Saṃyuktāgama veröffentlichte L. de La Vallée Poussin, Documents sanscrits de la seconde collection M.A. Stein. JRAS (1913) 569-581. 
of the Samyuktāgama and the Development of the Devatāsūtra. JIBS 31,1 [1982] 399-396<87-90>, und H. Matsumura, The Devat $\bar{a}-$ sūtra and Alpadevatāsūtra. JIBS 30,2 [1982] 988-982<54-60>, und ders., Notes on the Gilgit Manuscripts. JIBS 31,2 [1983] 856-854 $<128-130>$ ).

5.2.3. Gleiches gilt im Falle des Madhyamāgama:

- *Apramāda- und *Śikhālakasūtra (s. K. Matsuda, Newly Identified Buddhist Sanskrit Fragments in the National Archives Collection, Nepal. JIBS 39,1 [1990] $388<118>$, und ders., New Sanskrit Fragments of the Madhyama-āgama from the Cecil Bendall Manuscripts in the National Archives Collection, Kathmandu. JIBS 44,2 [1996] $868-862<113-119>$ )

- Upālisūtra (s. S. Lévi, Notes indiennes: Un fragment de l'Upāli Sūtra en sanskrit. JA 206 [1925] 26-35)

- *Rāhulasūtra (s. P. Skilling, Verses Associated With the *Rāhulasūtra. In: Suhrllekhāh. Festgabe für Helmut Eimer. [Indica et Tibetica 28]. Swisttal-Odendorf 1996, p. 201-226)

- Śsukasūtra (s. Hoernle 1916: 46-52).

5.2.4. Die die Mūlasarvāstivāda-Version des Ekottarāgama repräsentierenden Gilgit-Fragmente wurden von Tripathi 1995 (s. ders., SañgīiSūtra, Nipāta II, und Ekottarāgama-Parallelen. In: SWHL I/191199) ${ }^{146}$ und Y. Okubo, The Ekottara-āgama Fragments of the Gilgit Manuscript. Bukkyō gaku 35 (1982) 120-91<1-30>147 herausgegeben. ${ }^{148}$

5.2.5. Der Kanon der Mūlasarvāstivādins scheint keinen (eigentlichen) Kṣudrakāgama ausgebildet bzw. besessen zu haben. Denn das Divyāvadāna, ein Text dieser Schule (s.u.), spricht von einem "aus vier Teilen bestehenden Āgama" (ägamacatuștayam, [Ed. E.B. Cowell - R.A. Neil. Cambridge 1886] 17,22 und 322,8-9), die namentlich aufgezählt werden (samyuktaka, madhyama, dīrghāgama, ekottarikā, 322,10-13). ${ }^{149}$

146 Eine kürzere Fassung dieses Beitrags erschien in: Amalā Prajñā. Aspects of Buddhist Studies. Professor P.V. Bapat Felicitation Volume. Delhi 1989, p. 87-95.

147 Ders., A Study of the Sanskrit Fragments of the Ekottara-āgama. JIBS 31,2 (1983) 869-866 <115-118>, und A Study of the Ekottarika-ägama (II). JIBS 32,2 (1984) 706-705, beschäftigt sich (u.a.) mit der Beziehung der Ekottarāgama-Version der Gilgit-Handschriften zu der der Turfan-Texte.

148 Eine Studie eines Sūtras dieses Āgama legte H. Matsumura, One Sūtra of the Ekottarikāgama on Triśaraṇagamana and Pañcaśīla. Archív Orientálni 57 (1989) 359-371, vor.

149 Hierzu siehe Oldenberg 1967: I/929 und Lamotte 1988: 151-152. 
Gleichwohl erwähnen (etwa) Abhidharmakośa (Ed. P. Pradhan. Patna 1975) 466,5 und Abhidharmakośavyākhyā (Ed. U. Wogihara. Tokyo 1932-36) 33,32 - zwei weitere zu dieser Schule gehörende Texte - einen solchen, und es sind denn auch - zumeist in Form von Zitaten ${ }^{150}$ in oder als Bestandteil von größeren Werken - etliche Texte erhalten, die Parallelen oder Entsprechungen in der "Sammlung kleinerer [Texte]" anderer buddhistischer Schulen haben: ${ }^{151}$

- Arthavargīya und Pārāyaṇa (s. Schmithausen 1970: 95 mit n. 168, und F. Enomoto, Sarīrārthagāthā: A Collection of Canonical Verses in the Yogācārabhūmi. In: SWTF-Beiheft 2, p. 23)

- (die Parallelen in den Versen des Selasutta des Suttanipāta besitzende) Kaineyagāthā (s. J.-U. Hartmann, Der Pranāmastava. Ein Buddhastotra aus den Gilgit-Funden. In: BVS 285)

- Anavataptagāthā ${ }^{152}$ (s. Bechert 1961: 12-19 und M. Hofinger, Le congres du lac Anavatapta. I: Légendes des Anciens. Louvain 1954 [21982] und II: Légendes du Bouddha. Louvain 1990) ${ }^{153}$

- (das dem Buddhavaṃsa entsprechende) Bahubuddhasūtra (s. Bechert 1961: 18, n. 5)

- Udānavarga (s. Schmithausen 1970).

Auch Jātakas und Avadānas fanden in großer Zahl Aufnahme in den Vinaya dieser Schule, ${ }^{154}$ wo sie zumeist der Veranschaulichung der Ordensregeln dienen. Sekundär wurden dann aus diesem Text AvadānaSammlungen wie das Divyāvadāna ${ }^{155}$ oder das Avadānaśataka ${ }^{156}$ zu-

${ }^{150} \mathrm{Zu}$ Hinweisen auf die Existenz der Sthaviragāthā siehe Bechert 1961: 12.

${ }_{151}$ Eine Aufzählung solcher gibt Divyāvadāna: ... udānāt pārāyanāt satyadṛstah śailagāthā munigāthā arthavarḡ̄yāṇi ca sütrāṇi ..., 20,23-24 (dieselbe Reihe 34,20-35,1 mit zusätzlichem sthaviragāthāh vor śailagāth $\bar{a}[h]$ ); hierzu siehe Lamotte 1988: 162.

${ }_{152} \mathrm{Zu}$ neuem handschriftlichen Material s.o. n. 133.

${ }_{153} \mathrm{Zu}$ Hofingers Textbearbeitungen vergleiche man die Besprechung von $\mathrm{H}$. Bechert, ZDMG 142 (1992) 393-395.

154 Vgl. n. 129.

155 Zur Beziehung des Divyāvadāna zum Mūlasarvāstivāda-Vinaya siehe E. Huber, Études de littérature bouddhique. Les sources du Divyāvadāna. BEFEO 4 (1904) 698-726 und 6 (1906) 1-43 und 335-340, S. Lévi, Les éléments de formation du Divyāvadāna. T'oung pao 8 (1907) 105-122 und - zuletzt - S. Hiraoka, The Relation Between the Divyāvadāna and the Mülasarvāstivāda Vinaya. JIP 26 (1998) 419-434.

156 Trotz J.-U. Hartmann, Zur Frage der Schulzugehörigkeit des Avadānaśataka. In: SWHL I/219-224, ist nicht völlig gesichert, daß dieser Text tatsächlich zur Schule der Mūlasarvāstivādins gehört. 
sammengestellt. In diese wiederum wurden aber auch (Teile von) Sūtras aufgenommen, die aus dem Sūtrapițaka der Schule stammen, so etwa das Mahāparinirvāṇasūtra ${ }^{157}$ in das Divyāvadāna oder das Daśabalasūtra II (s.o. p. 53 mit n. 86), das Daharasūtra und das Mahāparinirvānasūutra in das Avadānaśataka. ${ }^{158}$

5.3. Was das Abhidharmapițaka anbelangt, so übernahmen die Mūlasarvāstivādins offenbar das der Sarvāstivādins (s.o. § 4.3) und überarbeiteten es in ihrem Sinne. Erhalten sind einzig ${ }^{159}$ Fragmente des Dharmaskandha und der Lokaprajñapti. ${ }^{160}$

Vom Dharmaskandha ist etwa ein Sechstel des Textes in einer GilgitHandschrift erhalten. ${ }^{161}$ Dieses wurde herausgegeben von S. Dietz unter dem Titel Fragmente des Dharmaskandha. Ein Abhidharma-Text in Sanskrit aus Gilgit. [AAWG 142]. Göttingen 1984. Weitere Fragmente machte K. Matsuda, Newly Identified Sanskrit Fragments of the Dharmaskandha in the Gilgit Manuscripts. Kyoto 1986, zugänglich. In dieser Arbeit ist auf den Seiten 37-43 eine Besprechung o.g. Edition von Dietz durch H. Sakurabe abgedruckt. ${ }^{162}$

Der eine Teil der Lokaprajñapti-Fragmente stammt aus Gilgit, der andere aus verschiedenen japanischen Tempeln (s. S. Dietz, A Brief Survey on the Sanskrit Fragments of the Lokaprajñaptiśāstra. Annual Memoirs of the Otani University 7 [1989] 79-86, K. Matsuda, Sanskrit Fragments of the Lokaprajñapti Preserved in Japanese Temples and Scindia Oriental Institute, Ujjain. Bukkyō gaku [Journal of Buddhist Studies] 14 [1982] 1-21, und A. Yuyama, Remarks on the Kōkiji Fragment of the Lokaprajñapti. In: India and the Ancient World. Professor

$15 \overline{7}$ Divyāvadāna 200-208 findet sich eine Passage des Mahāparinirvāṇasūtra, der im Pāli-Text das dritte Kapitel (DN II 102-121) entspricht (s. Oldenberg 1967: II/934-935 und Windisch 1895: 35-63). Die tibetische Übersetzung dieses Sūtra wurde in Umschrift herausgegeben von E. Waldschmidt, Das Mahāparinirvānasūtra. Berlin 1951. Ubersetzt wurde sie von W.W. Rockhill, The Life of Buddha and the Early History of His Order. London 1884, p. 123-147.

${ }_{158}$ Hierzu siehe Oldenberg 1967: II/986-989 und den n. 156 angeführten Artikel von Hartmann.

159 Zum Sangītiparyāya siehe p. 60, n. 118.

160 Eine Zusammenfasung dieses Textes findet sich im 3. Kapitel von Vasubandhus Abhidharmakośa(bhāṣya).

161 Siehe J. Takasaki, Remarks on the Sanskrit Fragments of the Abhidharmadharmaskandhapādaśāstra. JIBS 13,1 (1965) 411-403<33-41>.

162 Eine weitere wichtige Besprechung stammt aus der Feder von J.W. de Jong und wurde IIJ 30 (1987) 75-76 veröffentlicht. 
P.H.L. Eggermont Jubilee Volume. Leuven 1987, p. 215-227). Eine Ausgabe dieses Textmaterials bereitet derzeit Frau Dr. Dietz am Seminar für Indologie und Buddhismuskunde der Universität Göttingen vor. ${ }^{163}$

\section{Die MahāsāinghiKas}

6. Die Mahāsānghikas sollen - einer Nachricht (in der chinesischen Übersetzung) ihres Vinaya zufolge - ein aus vier Āgamas und einem Kṣudrakapițaka bestehendes Sūtrapițaka besessen haben, ${ }^{164}$ und häufig wird in ihrem Vinaya auch auf den Abhidharma oder die Mātṛkā Bezug genommen, ${ }^{165}$ obwohl eine der ceylonesischen Pāli-Chroniken zu berichten weiß, dass die Mahāsaṃgītikas, auf die diese Schule letztlich zurückzugehen scheint, den Abhidharma nicht (als autoritativ) anerkannt haben (s. Dīpavaṃsa V 37). ${ }^{166}$

6.1. Der Vinaya (T 1425) sowie das Bhikṣu- und das BhikṣuṇīPrātimokșasūtra (T 1426, 1427) dieser Schule liegen jeweils in chinesischer Übersetzung vor. ${ }^{167}$ Vom Sanskrit-Text des Vinaya wurden kleinste Reste in Nepal und Zentralasien gefunden. Veröffentlicht wurden sie von Lévi (1932: 4-8). Dass die karmavācanā-Fragmente der Schøyen-

163 Frau Dietz hat in Vorbereitung ihrer Textausgabe eine Reihe wichtiger Untersuchungen vorgelegt. Von diesen seien hier folgende genannt: Remarks on a Fragmentary List of Kings of Magadha in a Lokaprajñapti Fragment. WZKS 33 (1989) 121-128; Remarks on a Hitherto Unknown Cosmological Text in the Kanjur. $A O H 43$ (1989) 273-283; Die verschiedenen Versionen der Lokaprajñapti. In: XXIII. Deutscher Orientalistentag - Ausgewählte Vorträge. [ZDMG-Suppl. VII]. Stuttgart 1989, p. 489-497; Remarks on the Textual Transmission of Four Stanzas from the Lokaprajñaptiśāstra. In: Suhṛllekhāh. Festgabe für Helmut Eimer. [Indica et Tibetica 28]. Swisttal-Odendorf 1996, p. 7-15.

164 Siehe Lamotte 1988: 151.

165 Siehe Lamotte 1988: 181.

$166 \mathrm{Zu}$ dieser Stelle siehe O. von Hinüber, Vinaya und Abhidharma. StII 19 (1994) 112 mit n. 6 (vgl. auch Lamotte 1988: 181).

${ }_{167} \mathrm{Zu}$ den chinesischen Übersetzungen der Vinaya-Texte der Mahāsāṅghikas siehe Frauwallner 1956: 198-207, Hirakawa 1982: 9-10, Lamotte 1988: 169-170, Prebish 1994: 56-61 - dort sind neben Hirakawa 1982 weitere Übersetzungen in "europäische" Sprachen verzeichnet - und Yuyama 1979: 38-40. Zur Struktur des Skandhaka des Mahāsānghika-Vinaya siehe Sh. Sasaki, Buddhist Sects in the Aśoka Period (4). Bukkyō Kenkyū (Buddhist Studies) 23 (1994) 55-100. Wichtig ist, dass chinesische Übersetzungen von Mahāsāṅghika-Texten erhalten sind, deren uns erhaltene Originale der Schule der Mahāsānghika-Lokottaravādins angehören: Abhisamācārikā = T 1425, vol. XXII, 499a-514a, Bhikṣu-Prakīrṇaka = ibid., 412b499a, Bhikṣuṇi-Prakīrṇaka = ibid., 544c-549a (s. de Jong 1974: 63). 
Sammlung zu einer der Untergruppierungen der Mahāsāṅghika-Schule gehören, vermutet J.-I. Chung, Fragments of a Karmavācanā Collection. Karmavācanā for Ordination. In: Buddhist Manuscripts. Ed. by J. Braarvig. Vol. II. Oslo 2002, p. 229-237. ${ }^{168}$

6.2. Auch der Ekottar(ik)āgama ('T 125) der Mahāsāṅhikas liegt in chinesischer Übersetzung vor - dies ist zumindest die Meinung einer großen Zahl von Buddhologen. ${ }^{169}$

\section{Die Mahāsāinghika-Lokottaravādins}

7. Die Schule der Mahāsāṅghika-Lokottaravādins ist in erster Linie durch ihre "Buddhologie" bekannt geworden. Eine doketische Position vertretend, sah sie in Buddha ein überweltliches Wesen von unermesslicher Lebensdauer, das lediglich zum Wohle der irdischen Lebewesen in Gestalt eines (sterblichen) Menschen, nämlich des (historischen) Gautama Buddha, aufgetreten war.

7.1. Alle ${ }^{170}$ uns bekannten Texte der Mahāsānghika-Lokottaravādins

168 Ob auch die Sphuțārthā Śrīghanācārasaṃgrahațīkā - der Sanskrit-Text wurde nach einer Handschrift aus dem Kloster Ngor (Sammlung Sankrityayana) von Sanghasen Singh als 24. Band der TSWS (Patna 1983) herausgegeben - zur Schule der Mahāsānghikas gehört (so M. Prasad, A Comparative Study of the Abhisamācārikē. Patna 1984, p. 23, und M. Shimoda, The Sphutārthā Śrīghanācārasangrahațika and the Chinese Mahāsāinghika Vinaya. JIBS 39,1 [1990] 495-492<11-14>), ist zweifelhaft (s. Y. Ejima, Daishibukei Ritten Bonpon ni tsuite. In: Okuda Jiō Sensei Kiju Kinen Bukkyō Shisō Ronshū ["Studies in Buddhist Thought dedicated to Professor Jiō Okuda in Commemoration of his Seventy-Seventh Birthday"]. Kyōto 1976, p. 918f. [non vidi; Hinweis bei Yuyama 1979: 40 und Hu-von Hinüber 1994: 529]). Siehe jetzt G. Agostini, JIABS 26 (2003) 97-114.

169 Stellvertretend seien hier Waldschmidt 1989: 370-371, J. Bronkhorst, Dharma and Abhidharma. BSOAS 48 (1985) 312-315, und Schmithausen 1987: 321 und 378 genannt (vgl. auch Mayeda 1985: 102-103).

${ }_{170}$ Falls das von T. Brekke, The Caṃgīsūtra of the Mahāsāṃghika-Lokottaravādins. In: Buddhist Manuscripts. Ed. by J. Braarvig. Vol. I. Oslo 2000, p. 53-63, veröffentlichte Fragment des Caṅḡ̄sūtra tatsächlich zum Kanon der MahāsānghikaLokottaravādins gehört, wie sein Herausgeber behauptet (p. 54), ist diese Feststellung zu revidieren. J.-U. Hartmann, der "More Fragments of the Cangīsūtra" in Buddhist Manuscripts II (ed. J. Braarvig. Oslo 2002), p. 1-16 publizierte, läßt die Frage der Schulzugehörigkeit dieses Textes allerdings offen (hierzu s. auch D. Bouchers Besprechung der Buddhist Manuscripts [Vol. I] in IIJ 45 [2003] 248-249, der ibid. 258-259 generell vor "Schulzuschreibungen" außerhalb des Vinaya warnt). 
gehören deren Vinayapitaka an. ${ }^{171}$ Bemerkenswerterweise aber wurde kein Vinaya-Text dieser Schule ins Chinesische übersetzt (vgl. auch p. 71, n. 167).

7.1.1. Erhalten ist das Bhikṣuprātimokṣasūtra. Es wurde herausgegeben von W. Pachow und R. Mishra, The Prātimoksa-Sütra of the Mahāsāinghikas. Allahabad 1956, und - in verbesserter Form - von $\mathrm{N}$. Tatia, Prātimokṣasūtram of the Lokottaravādi-mahāsāinghika School. [TSWS 16]. Patna 1975. Zu der Eingangspartie dieses Textes siehe G. Roth, Notes on the Introduction of the Bhikṣu-Prātimokṣa-Sūtra of the Ārya-Mahāsāṃhika-Lokottaravādin. In: Studies in Pali and Buddhism. A Memorial Volume in Honour of Bhikkhu Jagdish Kashyap. Delhi 1979, p. 317-326. Eine Übersetzung dieser Einleitung legte W. Pachow, Translation of the Introductory Section of the PrātimokșaSūtra of the Mahāsānghikas. Journal of the Ganganatha Jha Research Institute 11/12 (1953/54) 243-248 (wiederabgedruckt in: W. Pachow - R. Mishra, op. cit., p. 49-54), vor, eine des ganzen Textes Prebish (1975).

7.1.2. Sowohl vom Bhikṣu- als auch vom Bhikṣuṇivinayavibhañga sind Fragmente erhalten. Erstere wurden herausgegeben ${ }^{172}$ und erläutert von O. von Hinüber, A Fragment of the Mahāsānghika-LokottaravādaVinaya from Bāmiyān. BEI 4 (1986) 295-303, E. Nolot, Derechef à propos d'un fragment du ? Mahāsāṃghika-Vinaya. BEI 6 (1988) 351358, und H. Matsumura, Analecta Indica. Review of Shinwa Women's College 24 (1991) 27-43. Allerdings wird die Zuordnung zu den Mahāsāṅghika-Lokottaravādins von H. Matsumura, Encore à propos d'un fragment du Mahāsāṃghika-vinaya. BEI 6 (1988) 343-350, in Zweifel gezogen. Unter Umständen gehören auch die von S. Karashima, A Fragment of the Prātimokṣa-Vibhangga of the Mahāsāṃhika-Lokottaravādins. In: Buddhist Manuscripts. Ed. by J. Braarvig. Vol I. Oslo 2000, p. 233-241, und derselbe, Two More folios of the PrātimokṣaVibhanga of the Mahāsāṃghika-Lokottaravādins. In: Buddhist Manuscripts II. (s. n. 170), p. 215-228, publizierten Fragmente aus dem Prātimokṣa-Vibhañga zum Kanon der Mahāsāṅghika-Lokottaravādins.

Der erhaltene Text des Bhikṣun̄ivinayavibhaṅga wurde von G. Roth unter dem Titel Bhikṣuñ-Vinaya (Manual of Discipline for Buddhist Nuns). Including Bhikṣuṇī-Prakīrṇaka and a Summary of the Bhikṣu-

171 Zum Vinaya der Mahāsāṅghika-Lokottaravādins s. Prebish 1994: 61-65 und Yuyama 1979: 40-43.

172 Der Text findet sich auch bei Lévi (1932: 11-12). 
Prakīrṇaka of the Ārya-Mahāsāṃghika-Lokottaravādin. [TSWS 12]. Patna 1970, herausgegeben, wozu derselbe Gelehrte einen Nachtrag in StIB 229-238 veröffentlichte. Zu dieser Edition vergleiche man die Besprechungen von J. Brough, BSOAS 36 (1976) 675-677, C. Caillat, JA 264 (1976) 240-243, O. von Hinüber, OLZ 72 (1977) 526-529, de Jong 1974 und dems., IIJ 16 (1975) 149-150. Eine Übersetzung legte E. Nolot, Règles de discipline des nonnes bouddhistes - Le Bhikșuñvinaya de l'école Mahāsāṃhika-Lokottaravādin. Paris 1991, vor, die von P.-S. Filliozat, BEFEO 79 (1992) 291ff., Ch. Chojnacki, BSOAS 56 (1993) 154ff., J.W. de Jong, IIJ 37 (1994) 375-378, und G. Roth, OLZ 90 (1995) 207-215, rezensiert wurde. ${ }^{173}$

7.1.3. Des weiteren sind mit dem Bhikṣuṇipprakīrṇaka und einer stichwortartigen Zusammenfassung des Bhikṣuprakīrṇaka (uddāna), mit der Abhisamācārikā und dem Mahāvastu weitere Vinaya-Texte dieser Schule erhalten. $\mathrm{Zu}$ den beiden erstgenannten Texten ${ }^{174}$ siehe oben § 7.1.2. Die Ausgabe der Abhisamācārikā durch B. Jinananda, Abhisamācārikā |Bhikșuprakīrnaka]. [TSWS 9]. Patna 1969, ${ }^{175}$ ist nun überholt durch die der Abhisamācārika-Dharma Study Group: (a) A Guide to the Facsimile Edition of the Abhisamāañrika-Dharma of the Mahāsāmghika-Lokottaravādin. Tokyo 1998, (b) Transcription of the Abhisamācārika-Dharma, Chapter V-VII. The Annual Report of the Institute for Comprehensive Studies of Buddhism (Taishō Daigaku Sōgō Bukkyō Kenkyūsho Nenpō) 21 (1999) 234-156 (s. auch Y. Matsunami, On the Manuscript of the "Abhisamācārikā". JIBS 45,2 [1997] 1034-1030<913>). Das erste Kapitel dieses Textes wurde von S. Singh und K. Minowa, Buddhist Studies (University of Delhi) 12 (1988) 113-146, ins Englische übersetzt (vgl. auch M. Nishimura, Abhisamācārikē I. $8 \sim 10$. In: Early Buddhism and Abhidharma Thought in Honour of Doctor Hajime Sakurabe. Kyoto 2002, p. 73-84). Die Abhisamācārikā ist auch in chinesischer Übersetzung erhalten (T 1425, vol. XXII, 499a-514a), und zwar als Teil der Übersetzung des Mahāsānghika-Vinaya (s. Yuyama

173 Sich an diesen Text anschließende Untersuchungen verzeichnet Yuyama (1979: 41 und 51).

174 Eine Passage des Bhikṣuprakīrṇaka wird in Śāntidevas Śikṣāsamuccaya (Ed. C. Bendall. St. Petersburg 1897-1902, p. 154,17-155,3) zitiert. Ausführlich hierzu A. Yuyama, The Bhikṣu-Prakīrnaka of the Mahāsāṃghika-Lokottaravādins quoted by Śñntideva in his Śiksāsamuccaya. Annual Report of the International Research Institute for Advanced Buddhology at Soka University 6 (2003) 3-17.

175 Auf die großen Schwächen dieser Textausgabe machte J.W. de Jong in seiner Besprechung, IIJ 16 (1975) 150-152, aufmerksam. 
1979: 41, Hirakawa 1982: 14 und de Jong, IIJ 16 [1975」 151). Mit dieser Übersetzung beschäftigt sich M. Nishimura, Über den Text der Abhisamācārikā. JIBS 33,1 (1984) 415-409<1-7>, ders., Die chinesische Fassung des zweiten Kapitels der Abhidharmasamācārikā aus dem Mahāsāṃhika-Vinaya (1). In: Religion and Culture. S. Saitō Felicitation Volume. Tokyo 1990, p. 842-821<47-68>, und ders., Die chinesische Fassung des zweiten Kapitels der Abhidharmasamācārikā aus dem Mahāsāmghika-Vinaya (2). Studies in Buddhism and Buddhist Culture 38 (1993) $1-18 .{ }^{176}$

7.2. Das Mahāvastu-Avadāna ${ }^{177}$ ist eine Textsammlung, in die (u.a.) verschiedene Texte des Sūtrapițaka aufgenommen wurden. Geschehen ist dies entweder in Form langer Passagen ${ }^{178}$

- zu nennen sind hier das Majjhimanikāya LXXXI entsprechende Jyotipālasūtra, Mahāvastu (ed. E. Senart) I 317,4-335,8, ${ }^{179}$ das Samyuttanikāya II 217-222 entsprechende Mahākāśyapasya-Vastupravrajyāsūtra, Mahāvastu III 47,10-56,5, ${ }^{180}$ das (u.a.) Dīghanikāya XIX entsprechende Mahāgovindīyasūtra, Mahāvastu III 197,11$224,9,{ }^{181}$

oder bloßer Verweise

- so wird Mahāvastu I 350,8 auf das u.a. Dīghanikāya XXI überlieferte Śakrapraśnasūtra (yathoktam bhagavatā śakrapraśneṣu) und Mahāvastu III 67,7 auf das (u.a.) Majjhimanikāya LXXIV überlieferte Dīrghanakhasūtra (d̄̄rghanakhasya parivrājakasya sūtram kartavyam) verwiesen. ${ }^{182}$

${ }_{176} \mathrm{Zu}$ der Studie von M. Prasad s.o. p. 72, n. 168.

177 Einen Überblick über die zu diesem Text veröffentlichte Sekundärliteratur gibt A. Yuyama, A Bibliography of the Mahāvastu-Avadāna. IIJ 11 (1968/69) 1121, und ders., The Mahāvastu-Avadāna in Old Palm-Leaf and Paper Manuscripts. I. Palm-Leaf Manuscripts. [Bibliotheca Codicum Asiaticorum 15]. Tokyo 2001.

178 Etliche solcher Passagen tragen keinen Texttitel, so Mahāvastu I 338,13348,7, das im Aggaññasutta des Dīghanikāya (III 84,26ff.) eine Parallele hat (s. Oldenberg 1967: II/1045), Mahāvastu II 115,6-132, das dem Mahāsaccakasūtra des Majjhimanikāya (XXXVI) entspricht, oder Mahāvastu III 281,11-286,7 / 415,6417,6, das Gegenstück zu Teilen des Mārasaṃyukta des Saṃyuttanikāya (s. J. Charpentier, Das Mārasaṃyutta im Mahāvastu. WZKM 23 [1909] 33-51).

179 Siehe Oldenberg 1967: II/1047 und 1052-1053.

180 Siehe Oldenberg 1967: II/1048, n. 2.

181 Siehe Oldenberg 1967: II/935-936 und 1047-1051.

182 Siehe Oldenberg 1967: II/937 und 1056. 
Ebenso fanden Teile des "Kșudrakāgama" Aufnahme. So entspricht Mahāvastu I 290,11-295,14 dem Ratanasutta des Khuddhakapātha. ${ }^{183}$ Und Mahāvastu I 357,5-359,17 werden Verse des Khaḍgaviṣāṇasūtra - zu vergleichenden Texten s. o. §3.2 - und Mahāvastu II 198,3-199,18 (samt 166,3) resp. II 238,3-240,17 solche, die denen des Pabbajjāsutta, Suttanipāta 405-424, resp. des Padhānasutta, Suttanipāta 425-449, entsprechen, angeführt (hierzu s. Windisch 1895: 316-337). Des weiteren ist der Nālakapraśna, Mahāvastu III 386,18-389,11, das Gegenstück des Nālakasutta, Suttanipāta 699-723, und Mahāvastu III 394,13-401, 18 das des Sabhiyasutta, Suttanipāta 91-102. ${ }^{184}$ Darüber hinaus finden sich viele Einzelverse, die Parallelen im Suttanipāta besitzen: Mahāvastu III 417,15-18 / 418,2-5 = Suttanipāta 33-34, Mahāvastu III 418, 13-15 = Suttanipāta 492, 494 (s. Oldenberg 1967: II/938).

Besonders viele Parallelen gibt es zwischen Mahāvastu und Dhammapada. So entsprechen die Verse Mahāvastu II 424,8*-9* Dhp. 126, III 91,19*-92,2* Dhp. 179 und 180, III 376,10*-13* Dhp. 146, III 412,15*22* Dhp. 141-142, III 420,12*-13* Dhp. 183, III 421,10*-11* Dhp. 369, III 421,18*-19* Dhp. 368, III 422,4*-5* Dhp. 364, III 422,8*-11* Dhp. 271-272, III 422,12*-15* Dhp. 266-267, III 423,1*-2* Dhp 362cd, III $423,3 *-6 *$ Dhp. $360-361$ und III 434,13*-436,17* Dhp 100-115 (s. Oldenberg 1967: II/938-940). ${ }^{185}$ Aber auch in das Bhikṣuprātimokṣasūtra und in die Abhisamācārikā fanden Verse des "Dharmapada" Eingang.

Auch viele Jātakass ${ }^{186}$ wurden ins Mahāvastu aufgenommen. ${ }^{187}$ Und überdies finden sich Textpassagen, die Parallen im Vimānavatthu und

183 Siehe Oldenberg 1967: II/941 und Lamotte 1988: 157.

184 Siehe Oldenberg 1967: II/938 und 1043-1044.

185 Der Mahāvastu II 212,18 als yathoktam bhagavatā dharmapade (ähnlich 156, 15) eingeführte Vers gatim mṛānāạ pavanam ākāsam pakșinām gatih / dharmo gatir vibhāgūyānām nirvānam arhatām gatih, II 212,19*-20* ( III 156,16*-17*), begegnet im Theravāda-Kanon Vin V 149,22*_23* (hierzu s. Mizuno 1979: 262-263).

186 Diese Jātakas sind fast alle im jungen Stil A verfaßt (hierzu s.u. n. 190). Sie zeigen die die Vergangenheits- resp. Gegenwartserzählung einleitenden Formeln bhūtapūrvam ... und syāt khalu punah - diese teilen sie mit den Jātakas des Suttapițaka der Theravādins. Geneuert ist mit tat kasya hetoh im Samodhāna (s. O. von Hinüber, Entstehung und Aufbau der Jātaka-Sammlung. [AAWL 1998/7]. Stuttgart 1998, p. 193).

187 Unter Hinweis auf die Parallele im Pāli-Jātaka sind diese von A. Barth, Journal des savants (1899) 625-627 (= Oeuvre August Barth. Tome V. Paris 1927, p. 36-38), und S. d'Oldenburg, On the Buddhist Jātakas. JRAS (1893) 335-340, verzeichnet. 
im Buddhavaṃsa des Theravāda-Kanon besitzen. So entspricht Mahāvastu II 189,1-195,3 dem Kaṇthakavimāna ( $V_{V}$ 1164-1191), ${ }^{188}$ und Mahāvastu I 250,5-252,18 hat in Buddhavamsa IV ein Gegenstück (wobei I 251,11-12 = Bv V 15 und I 251,18-252,1 = Bv II 65-68). ${ }^{189}$

Und so werden wir denn davon ausgehen dürfen, dass auch die Mahāsāṅghika-Lokottaravādins ein (vollständiges) Sūtrapiṭaka besessen haben. ${ }^{190}$

7.3. Offenbar aber fehlte ein Abhidharmapitaka, wenigstens unter diesem Namen. ${ }^{191}$

\section{Die Mahīśśasakas}

8. Der Vinaya der Mahīśāsakas ist in chinesischer Übersetzung (T 1421) ${ }^{192}$ erhalten, des weiteren das Bhikṣu- und das Bhikṣuṇ̄-Prātimokṣasūtra und die Bhikṣu-Karmavācanā als Einzeltexte ('T 1422-1424). Ansonsten ist vom Kanon der Mahīśāsakas, der dem der Theravādins ähnlich gewesen zu sein scheint ${ }^{193}$ und dessen Sūtrapițaka - einer Angabe in der chinesischen Übersetzung ihres Vinaya zufolge - aus vier Āgamas und einem Kṣudrakapițaka bestand, ${ }^{194}$ nichts erhalten. Von AbhidharmaTexten oder gar einem Abhidharmapitaka dieser Schule ist nichts bekannt. ${ }^{195}$

188 Hierzu siehe H. Kern, Deutung einer mißverstandenen Stelle im Mahāvastu. Indogermanische Forschungen 31 (1912) 194-197, und Oldenberg 1967: II/942 und 1062 .

189 Siehe Oldenberg 1967: II/942 mit n. 1.

190 Man weiß seit den Mahāvastu-Forschungen Oldenbergs, dass sich im Mahāvastu drei Textschichten aufs deutlichste voneinander abheben: eine offenkundig junge Schicht (Stil A), "eine altkanonische Schicht (Stil B) und eine weitere, die kanonische Diktion in jüngerer Handhabung repräsentierende Schicht (Stil B ${ }^{1}$ )" (Oldenberg 1967: II/985). Oldenberg schloss ganz zu Recht, dass "dem Verfasser oder Anordner des Mahāvastu eine Sammlung in B-Stil verfaßter, offenbar dem Pālikanon sehr nahestehender Texte vorlag: der Kanon der Schule, welcher er selbst angehörte" (H. Oldenberg, Der indische Buddhismus [1910-1913]. Archiv für Religionswissenschaft 17 [1914] 620).

191 Siehe Lamotte 1988: 181.

192 Zu diesem Vinaya siehe Frauwallner 1956: 182-184, Hirakawa 1982: 10-11, Lamotte 1988: 170, Prebish 1994: 66-70 und Yuyama 1979: 37-38. Zu Einzelheiten zur chinesischen Übersetzung sei auch auf Hu-von Hinüber (1994: 100-101) verwiesen.

193 Siehe Schmithausen 1970: 95 mit n. 166.

194 Siehe Lamotte 1988: 151.

195 Siehe Lamotte 1988: 181. 


\section{Die SĀmmitīyas}

9. Mit dem von Buddhatrāta verfaßten Kommentar zum Bhikṣuprātimokșasūtra, der jedoch nur noch in chinesischer Übersetzung durch Paramārtha aus dem Jahre 568 n. Chr. (T 1461) erhalten ist, ${ }^{196}$ dem Patna-Dhammapada ${ }^{197}$ und dem ebenfalls nur in chinesischer Übersetzung (T 1649) vorliegenden Sāmmit̄̄ya(nikāya)śāstra, ${ }^{198}$ einem Abhidharma-Text, kennen wir lediglich drei Texte der Sāmmitīyas ${ }^{199}$ - eines Zweiges der Vātsīputrīyas -, die zur Zeit der Indien-Reise des chinesischen Pilgers Xuan-zang (629-644) eine der wichtigsten Schulen des indischen Buddhismus bildeten. ${ }^{200}$ Doch enthält das letztgenannte Werk sowie Daśabalaśrīmitras Samskrtāsaṃskṛtaviniścaya zahlreiche, wenn auch kurze Zitate aus den Āgamas dieser Schule. ${ }^{201}$ Und Yi-jing, der 50 Jahre nach Xuan-zang Indien bereiste, weiß denn auch zu berichten, dass ihr Tripițaka eine Textlänge von umgerechnet 200.000 Versen

196 Siehe Yuyama 1979: 43, Prebish 1994: 76, Thiên Châu 1999: 117-122 und Skilling 1997: 103 mit n. 81.

${ }_{197}$ Hierzu siehe T. Namikawa, The Transmission of the New Material Dharmapada and the Sect to Which it Belonged. Bukkyō Kenkȳ̄ (Buddhist Studies) 22 (1993) 151-166, und Skilling 1997. Das Patna-Dharmapada wurde wiederholt herausgegeben: N.S. Shukla, The Buddhist Hybrid Sanskrit Dharmapada. Patna 1979; Gustav Roth, Particular features of the language of the Ārya-MahāsāṃghikaLokottaravādins and their importance for early Buddhist tradition. In: Die Sprache der ältesten buddhistischen Überlieferung. (Symposien zur Buddhismusforschung II). Hrsg. von Heinz Bechert. $[A A W G$ 117]. Göttingen 1980, p. 97-135 (= Indian Studies, p. 308-346 [mit addenda et corrigenda p. 452-455]; M. Cone, The Patna Dhammapada, Transcribed and Translated with a Commentary. Cambridge 1986 (unpubl. Dissertation, deren Textteil unter dem Titel "Patna Dharmapada. Part I: Text" JPTS 13 [1989] 101-217 abgedruckt wurde); K. Mizuno, A Study of the Buddhist Hybrid Sanskrit Dharmapada (II). Bukkyō Kenkȳu (Buddhist Studies) 19 (1990) 1-66.

198 Hierzu siehe Thiên Châu 1999: 99-117. Eine Übersetzung dieses Textes legte K. Venkataramanan, Sāmmitīyanikāya Śāstra. Visva-Bharati Annals 5 (1953) 155242 , vor.

${ }_{199} \mathrm{Zu}$ dieser Schule siehe insbesondere P. Skilling, History and Tenets of the Sāmmatīya School. Linh-So'n - Publication d'Études Bouddhologiques 19 (1982) 3852, und Thiên Châu 1999: 123-225.

200 Zur jüngeren Literatur der Sāmmitīyas siehe - außer den bereits genannten Arbeiten - N. Dutt, The Sammitiyas and their Pudgalavāda. Maha Bodhi 79 (1971) $129-136$.

201 Siehe P. Skilling, The Saṃskṛtāsaṃskṛta-Viniścaya of Daśabalaśrīmitra. Buddhist Studies Review 4 (1987) 17-18, und ders. 1997: 104. Siehe auch oben p. 50, n. 71 . 
besitzt, von denen 30.000 auf das Vinayapiṭaka ${ }^{202}$ entfallen (s. Lamotte 1988: 544 und Thiên Châu 1999: 18-31).

\section{DIE KĀŚSYPĀYAS}

10. An Texten der Kāśyapīyas ${ }^{203}$ ist uns einzig und allein das Bhikṣuprātimokṣasūtra in einer chinesischen Übersetzung (T 1460) bekannt. ${ }^{204}$

\section{Literatur- und Abkürzungsverzeichnis}

Banerjee 1977

Bechert 1957

Bechert 1961

Bechert 1982

Bechert 1998

Bernhard 1970
A.Ch. Banerjee, Two Buddhist Vinaya Texts in Sanskrit. Calcutta 1977.

H. Bechert, Zur Geschichte der buddhistischen Sekten in Indien und Ceylon. La Nouvelle Clio 7-9 (1955-1957) 311360 .

Ders., Bruchstücke buddhistischer Verssammlungen aus zentralasiatischen Handschriften. 1. Die Anavataptagāthā und die Sthaviragāthā. [STT VI]. Berlin 1961.

Ders., On the Identification of Buddhist Schools in Early Sri Lanka. In: Indology and Law. Studies in Honour of Professor J. Duncan M. Derrett. Wiesbaden 1982, p. 60-76. Ders., Remarks on Buddhist Sanskrit Literature in Sri Lanka from the 9th Century until the End of the Dambadeniya Period. In: Sūryacandrāya. Essays in Honour of Akira Yuyama on the Occasion of his 65th Birthday. [Indica et Tibetica 35]. Swisttal-Odendorf 1998, p. 1-8.

F. Bernhard, Gāndhārī and the Buddhist Mission in Central Asia. In: Añjali. Papers on Indology and Buddhism. A Felicitation Volume presented to Oliver Hector de Alwis Wijesekera on His Sixtieth Birthday. Peradeniya 1970, p. $55-62$.

202 Zum Vinaya der Sāmmitīyas siehe Hirakawa 1982: 5, Prebish 1994: 76 und Yuyama 1979: 43.

203 Bei den Kāśyapīyas und den Haimavatas handelt es sich nicht um dieselbe buddhistische Schule, wie dies A.K. Warder, Indian Buddhism. Delhi 1970, p. 288, behauptet. Den Haimavatas schreibt Lamotte (1988: 135 und 171) die chinesische Übersetzung eines Vinayavibhanga (Vinayamātṛkā, T 1463) zu. Ist dies richtig wozu man allerdings Yuyama 1979: 44 vergleiche -, wären uns Einzelheiten zur Struktur des Kanons dieser Schule bekannt: Das Sūtrapițaka hätte aus vier Āgamas und dem Kṣudrakapițaka und der Abhidharma aus fünf Teilen bestanden (s. Lamotte 1988: 151, 160 und 180).

204 Siehe Hirakawa 1982: 5 und 12, Prebish 1994: 76 und Yuyama 1979: 43. 
$B V S$

Chung 1998

Couvreur 1967

Cox 1998

$E B$

Enomoto 1994

$E R$

Frauwallner 1956

Gnoli 1977

Gnoli 1978

Gunawardana 1979

Härtel 1956

Hartmann 1989

Hartmann 1998

Hartmann 1999

Hartmann 2000

Hartmann 2002
Bauddhavidyāsudhākarah. Studies in Honour of Heinz Bechert on the Occasion of His 65th Birthday, ed. P. Kieffer-Pülz and J.-U. Hartmann. [Indica et Tibetica 30]. Swisttal-Odendorf 1997.

J.-I. Chung, Die Pravāranā in den kanonischen Vinaya-Texten der Mūlasarvāstivādin und der Sarvāstivādin. [SWTFBeiheft 7]. Göttingen 1998.

W. Couvreur, Nieuwe fragmenten van het Catuṣpariṣat-, Mahāparinirvāṇa-, Mahāsudarśana- en Mahāvadānasūtra. Orientalia Gandensia 4 (1967) 167-173.

C. Cox, Kaśmīra: Vaibhāșika Orthodoxy. In: Ch. Willemen - B. Dessein - C. Cox, Sarvāstivāda Buddhist Scholasticism. [HdO II/11]. Leiden 1998, p. 138-254.

Encyclopaedia of Buddhism. Edited by G.P. Malalasekera et al. Colombo $1961 \mathrm{ff}$.

F. Enomoto, A Comprehensive Study of the Chinese Samyuktăgama. Indic Texts Corresponding to the Chinese Samyuktāgama as Found in the Sarvāstivāda-Mūlasarvāstivāda Literature. Part 1: *Samgītanipāta. Kyoto 1994.

The Encyclopedia of Religion. Edited by M. Eliade. New York 1987.

E. Frauwallner, The Earliest Vinaya and the Beginnings of Buddhist Literature. [Serie Orientale Roma VIII]. Rom 1956.

R. Gnoli, The Gilgit Manuscript of the Sanghabhedavastu. Pt. I-II. [Serie Orientale Roma XLIX]. Rom 1977-1978.

Ders., The Gilgit Manuscript of the Śayanāsanavastu and the Adhikaranavastu. [Serie Orientale Roma L]. Rom 1978.

R.A.L.H. Gunawardana, Robe and Plough. Monasticism and Economic Interest in Early Medieval Sri Lanka. Tucson 1979 .

H. Härtel, Karmavācanā. Formulare für den Gebrauch im buddhistischen Gemeindeleben aus ostturkestanischen Sanskrit-Handschriften. [STT III]. Berlin 1956.

J.-U. Hartmann. Fragmente aus dem Dīrghāgama der Sarvāstivādins. In: SWTF-Beiheft 2, p. 38-67.

Ders., Sanskrit Fragments from the Ágamas (I): The Angulimālāsūtra. IT 23/24 (1997/1998) 351-362.

Ders., Buddhist Sanskrit Texts from Northern Turkestan and Their Relation to the Chinese Tripitaka. In: Buddhism Across Boundaries. Chinese Buddhism and the Western Regions. Sanchung (Taiwan) 1999, p. 107-136.

Ders., Zu einer neuen Handschrift des Dīrghāgama. In: VKK 359-367.

Ders., Further Remarks on the New Manuscript of the Dīrghāgama. Journal of the International College for Advanced Buddhist Studies 5 (2002) 133-150. 
Hartmann -

Wille 1992

Hartmann -

Wille 1997

von Hinüber 1982

von Hinüber 1985

von Hinüber 1996

Hirakawa 1982

Hirakawa 1990

Hoernle 1916

Hoffmann 1939

Hu-von Hinüber 1994

de Jong 1966

de Jong 1968

de Jong 1974

de Jong 1979

Kieffer-Pülz 1992
J.-U. Hartmann - K. Wille, Die nordturkistanischen Sanskrit-Handschriften der Sammlung Hoernle (Funde buddhistischer Sanskrit-Handschriften II). In: SWTF-Beiheft 4, p. 9-63.

Dies., Die nordturkistanischen Sanskrit-Handschriften der Sammlung Pelliot (Funde buddhistischer Sanskrit-Handschriften IV). In: SWTF-Beiheft 8, p. 131-182.

O. von Hinüber, Upāli's Verses in the Majjhimanikāya and the Madhyamāgama. In: Indological and Buddhist Studies. Volume in Honour of Professor J.W. de Jong on his Sixtieth Birthday. Canberra 1982, p. 243-251.

Ders., Die Bestimmung der Schulzugehörigkeit buddhistischer Texte nach sprachlichen Kriterien. In: SWHL I/5775 .

Ders., A Handbook of Pāli Literature. Berlin - New York 1996.

A. Hirakawa. Monastic Discipline for the Buddhist Nuns. An English Translation of the Chinese Text of the Mahāsāṃhika-Bhikṣun̄ī-Vinaya. Patna 1982.

Ders., A History of Indian Buddhism. From Śākyamuni to Early Mahāyāna. Translated and edited by Paul Groner. Hawaii 1990.

A.F.R. Hoernle, Manuscript Remains of Buddhist Literature Found in Eastern Turkestan. Oxford 1916 (Reprint: St. Leonhards - Amsterdam 1970).

H. Hoffimann, Bruchstücke des Āțānātikasūtra aus dem zentralasiatischen Sanskritkanon der Buddhisten. [Kleinere Sanskrit-Texte V]. Leipzig 1939 (vgl. Sander 1987).

H. Hu-von Hinüber, Das Poșadhavastu. Vorschriften für die buddhistische Beichtfeier im Vinaya der Mūlasarvāstivādins. Reinbek 1994.

J. W. de Jong, The Daśottarasūtra. In: Indian and Buddhist Studies in Honour of Professor Kanakura. Kyoto 1966, p. 3-25 (= de Jong 1979: 251-274).

Ders., Les Sūtrapitaka des Sarvāstivādin et des Mūlasarvāstivādin. In: Mélanges d'indianisme à la mémoire de Louis Renou. Paris 1968, p. 395-402 (= de Jong 1979: 229236).

Ders., Notes on the Bhikṣuñ̄-Vinaya of the Mahāsāṃghikas. In: Buddhist Studies in Honour of I.B. Horner. Dordrecht 1974, p. 63-70.

Ders., Buddhist Studies, ed. G. Schopen. Berkeley 1979.

P. Kieffer-Pülz, Die Sìmā. Vorschriften zur Regelung der buddhistischen Gemeindegrenze in älteren buddhistischen Texten. [Monographien zur indischen Archäologie, Kunst und Philologie 8]. Berlin 1992. 
Lamotte 1970

Lamotte 1988

Lévi 1932

Matsumura 1988

Mayeda 1985

Mittal 1962

Mizuno 1979

Nakamura 1996

Norman 1993

Oberlies 2000

Oldenberg 1967

Panglung 1981

Prebish 1975

Prebish 1994

Rosen 1959

Salomon 1999

Sander 1979

Sander 1985

Sander 1987
É. Lamotte, Le traité de la grande vertu de sagesse. Tome III. Louvain 1970.

Ders., History of Indian Buddhism. From the Origins to the Śaka Era. Translated from the French by Sara Webb-Boin. Louvain-La-Neuve 1988.

S. Lévi, Note sur des manuscripts sanscrits provenant du Bamiyan (Afghanistan) et de Gilgit (Cachemire). JA 220 (1932) 1-45.

H. Matsumura, The Mahāsudarśanāvad̄̄na and the Mahāsudarśanasūtra. Delhi 1988.

E. Mayeda, Japanese Studies on the Schools of the Chinese Āgamas. In: SWHL I/94-103.

K. Mittal, Dogmatische Begriffsreihen im älteren Buddhismus. I: Fragmente des Daśottarasūtra aus zentralasiatischen Sanskrit-Handschriften. [STT IV]. Berlin 1962.

K. Mizuno, Dharmapadas of Various Buddhist Schools. In: Studies in Pali and Buddhism. A Memorial Volume in Honour of Bhikkhu Jagdish Kashyap. Delhi 1979, p. 255-267.

H. Nakamura, Indian Buddhism. Delhi 1996.

K.R. Norman, Collected Papers. Volume IV. Oxford 1993.

Th. Oberlies, Heilige Schriften des Buddhismus. In: Heilige Schriften. Eine Einführung. Hrsg. von Udo Tworuschka. Darmstadt 2000, p. 167-196.

H. Oldenberg, Kleine Schriften. Teil I-II. Hrsg. von Klaus L. Janert. [Glasenapp-Stiftung 1,1-2]. Wiesbaden 1967.

Jampa Losang Panglung, Erzählstoffe des MūlasarvāstivādaVinaya. Analysiert auf Grund der tibetischen Übersetzung [Studia Philologica Buddhica, Monograph Series 3]. Tokyo 1981.

Ch.S. Prebish, Buddhist Monastic Discipline. The Sanskrit Prātimokṣa Sūtras of the Mahāsāṃghikas and Mūlasarvāstivādins. Pennsylvania - London 1975.

Ders., A Survey of Vinaya Literature. Taipei 1994.

V. Rosen, Der Vinayavibhainga zum Bhikṣuprātimokṣa der Sarvāstivādins. [ST'T II]. Berlin 1959.

R. Salomon, Ancient Buddhist Scrolls from Gandhāra. Seattle 1999.

L. Sander, Buddhist Literature in Central Asia. In: EB IV $/ 52-75$.

Dies., Pariṣad und parṣad in Vinaya- und Hīnayāna-SūtraTexten aus den Turfanfunden und aus Gilgit. In: $S W H L$ I/144-160.

Dies., Nachträge zu 'Kleinere Sanskrit-Texte, Hefte III V'. In: Kleinere Sanskrit-Texte V und Nachträge. Monographien zur indischen Archäologie, Kunst und Philologie 3]. Stuttgart 1987, p. 123-212. 
Sander 1991

Schmidt 1989

Schmithausen 1970

Schmithausen 1987

Schmithausen 1997

Schmithausen 2000

Schmithausen 2002

SHT I-VIII

von Simson 1986

von Simson 2000

Skilling 1997

Stache-Rosen 1968

Stache-Rosen 1984

StIB

$S T T$

SWHL I

SWHL II

SWTF-Beiheft

SWTF-Beiheft 1

SWTF-Beiheft 2
Dies., The Earliest Manuscripts from Central Asia and the Sarvāstivāda Mission. In: Corolla Iranica. Papers in Honour of Prof. Dr. David Neil MacKenzie. Frankfurt 1991 , p. $133-150$.

K.T. Schmidt, Der Schlußteil des Prātimokșasūtra der Sarvāstivādins. [STT XIII]. Göttingen 1989.

L. Schmithausen, $\mathrm{Zu}$ den Rezensionen des Udānavargah. WZKSO 14 (1970) 47-124.

Ders., Beiträge zur Schulzugehörigkeit und Textgeschichte kanonischer und postkanonischer buddhistischer Materialien. In: SWHL II/304-406.

Ders., Maitrī and Magic. Aspects of the Buddhist Attitude Toward the Dangerous in Nature. Wien 1997.

Ders., Zwei Fragmente aus dem Prakarana. In: VRK 481492.

Ders., Ein weiteres Fragment aus dem Prakarana: SHT VII 1697. WZKS 46 (2002) 51-103.

Sanskrithandschriften aus den Turfanfunden. Teil 1-8. Wiesbaden - Stuttgart 1965-2000.

G. von Simson, Prātimokșasūtra der Sarvāstivādins. Teil I. [STT XI]. Göttingen 1986.

Ders., Prātimoksasūtra der Sarvāstivādins. Teil II: Kritische Textausgabe, Übersetzung, Wortindex sowie Nachträge zu Teil I. [STT XI]. Göttingen 2000.

P. Skilling, On the School-Affiliation of the "Patna Dhammapada". JPTS 23 (1997) 83-122.

V. Stache-Rosen, Dogmatische Begriffsreihen im älteren Buddhismus II. Das Sañgittisūtra und sein Kommentar Sangītiparyāya. Teil I und II. [ST'T IX]. Berlin 1968.

Dies., Upālipariprcchāsūtra. Ein Text zur buddhistischen Ordensdisziplin. Hrsg. von Heinz Bechert. [AAWG 140]. Göttingen 1984.

Studien zur Indologie und Buddhismuskunde. Festgabe des Seminars für Indologie und Buddhismuskunde für Professor Dr. Heinz Bechert. [Indica et Tibetica 22]. Bonn 1993. Sanskrittexte aus den Turfanfunden.

Zur Schulzugehörigkeit von Werken der Hīnayāna-Literatur. Erster Teil (Symposien zur Buddhismusforschung III,1). Hrsg. von Heinz Bechert. [AAWG 149]. Göttingen 1985.

Zur Schulzugehörigkeit von Werken der Hīnayāna-Literatur. Zweiter Teil (Symposien zur Buddhismusforschung III,2). Hrsg. von Heinz Bechert. [AAWG 154]. Göttingen 1987. Beiheft zum Sanskrit-Wörterbuch der buddhistischen Texte aus den Turfanfunden.

Kanonische Zitate im Abhidharmakośabhāṣya des Vasubandhu. Bearbeitet von Bhikkhu Pāsādika. Göttingen 1989. Sanskrit-Texte aus dem buddhistischen Kanon: Neuentdekkungen und Neueditionen. Erste Folge. Göttingen 1989. 
SWTF-Beiheft 4

SWTF-Beiheft 5

SWTF-Beiheft 6

SWTF-Beiheft 8

SWTF-Beiheft 9

Thiên Châu 1999

Tripathi 1995

TSWS

VRK

Waldschmidt 1926

Waldschmidt 1932

Waldschmidt 1967

Waldschmidt 1989

Wille 1990

Windisch 1895

Yuyama 1979
Sanskrit-Texte aus dem buddhistischen Kanon: Neuentdekkungen und Neueditionen. Zweite Folge. Göttingen 1992. Untersuchungen zur buddhistischen Literatur [I]. Göttingen 1994.

Sanskrit-Texte aus dem buddhistischen Kanon: Neuentdekkungen und Neueditionen. Dritte Folge. Göttingen 1996.

Untersuchungen zur buddhistischen Literatur. Zweite Folge. Göttingen 1997.

Sanskrit-Texte aus dem buddhistischen Kanon: Neuentdekkungen und Neueditionen. Vierte Folge. Göttingen 2002.

Bhikshu Thich Thiên Châu, The Literature of the Personalists of Early Buddhism. Delhi 1999.

Ch.B. Tripathi, Ekottarāgama-Fragmente der Gilgit-Handschrift. Reinbek 1995.

Tibetan Sanskrit Works Series. Patna: Kashi Prasad Jayaswal Research Institute.

Vividharatnakarandaka. Festgabe für Adelheid Mette. Hrsg. von Ch. Chojnacki et al. [Indica et Tibetica 37]. SwisttalOdendorf 2000.

E. Waldschmidt, Bruchstücke des Bhikșuñ̄-Prātimokșa der Sarvāstivādins. Leipzig 1926 (Nachdruck: Wiesbaden 1979). Ders., Bruchstücke buddhistischer Sūtras aus dem zentralasiatischen Sanskritkanon. Leipzig 1932 (Nachdruck: Wiesbaden 1979).

Ders., Von Ceylon bis Turfan. Studien zur Geschichte, Literatur, Religion und Kunst des indischen Kulturraums. Göttingen 1967.

Ders., Ausgewählte kleine Schriften. Hrsg. von Heinz Bechert und Petra Kieffer-Pülz. [Glasenapp-Stiftung 29]. Stuttgart 1989.

K. Wille, Die handschriftliche Überlieferung des Vinayavastu der Mūlasarvāstivādins. [VOHD-Supplement 30]. Stuttgart 1990.

E. Windisch, Māra und Buddha. Leipzig 1895.

A. Yuyama, Systematische Übersicht über die buddhistische Sanskrit-Literatur (hrsg. von H. Bechert). Erster Teil: Vinaya-Texte. Wiesbaden 1979. 